\title{
Circularity Brokers: Digital Platform Organizations and Waste Recovery in Food Supply Chains
}

\author{
Francesca Ciulli ${ }^{1}$. Ans Kolk ${ }^{1} \cdot$ Siri Boe-Lillegraven ${ }^{1}$
}

Received: 9 July 2018 / Accepted: 11 April 2019 / Published online: 19 April 2019

(c) The Author(s) 2019

\begin{abstract}
In recent years, researchers and practitioners have increasingly paid attention to food waste, which is seen as highly unethical given its negative environmental and societal implications. Waste recovery is dependent on the creation of connections along the supply chain, so that actors with goods at risk of becoming waste can transfer them to those who may be able to use them as inputs or for their own consumption. Such waste recovery is, however, often hampered by what we call 'circularity holes', i.e., missing linkages between waste generators and potential receivers. A new type of actor, the digital platform organization, has recently taken on a brokerage function to bridge circularity holes, particularly in the food supply chain. Yet, extant literature has overlooked this novel type of brokerage that exploits digital technology for the transfer and recovery of discarded resources between supply chain actors. Our study investigates this actor, conceptualized as a 'circularity broker', and thus unites network research and circular supply chain research. Focusing on the food supply chain, we adopt an interpretive inductive theory-building approach to uncover how platform organizations foster the recovery of waste by bridging circularity holes. We identify and explicate six brokerage roles, i.e., connecting, informing, protecting, mobilizing, integrating and measuring, and discuss them in relation to extant literature, highlighting novelties compared to earlier studies. The final section reflects on contributions, implications, limitations and areas for further research.
\end{abstract}

Keywords Circularity brokers · Digital platforms · Food waste recovery $\cdot$ Supply chains

\section{Introduction}

According to the United Nations Food and Agriculture Organization (FAO 2017), one-third of the food annually produced for human consumption in the world is wasted. As emphasized by scholars and practitioners, food waste is profoundly unethical in view of the fact that one billion people in the world currently suffer from food deprivation (Ribeiro et al. 2018; World Bank 2014). In addition, food waste has significant negative impacts on the environment, due to disposal and landfilling, as well as the overproduction and overexploitation of natural resources that it implies (Devin and Richards 2018; FAO 2011). Until recently, the issue of waste in the food industry, and in other sectors, was seen as an inevitable externality. Over the last few years,

Ans Kolk

akolk@uva.nl

http://www.anskolk.eu

1 University of Amsterdam Business School, Plantage Muidergracht 12, 1018 TV Amsterdam, The Netherlands however, the waste problem has increasingly been acknowledged as an indication of failure of the existing economic model. This understanding has been particularly triggered by the emergence of a new economic paradigm, the circular economy, which promotes "a new approach to sustainability" (Murray et al. 2017, p. 370) aiming to eliminate waste (Ellen MacArthur Foundation 2013). A core principle of the circular economy is the "waste-as-food" concept (Murray et al. 2017), which indicates that the waste of one actor can be used as a resource by one or more others. Thus, waste recovery is critically contingent on the creation of ties between organizations and/or individuals for the transfer of goods at risk of becoming waste.

Extant sustainability literature has illustrated how the responsibility for waste, particularly food waste, is distributed along the supply chain. The absence of suitable ties between supply chain actors hinders an efficient and effective

\footnotetext{
1 We regard sustainability as covering the three pillars, i.e., the environmental, social and economic dimensions. However, in line with Murray et al. (2017), we explicitly recognize the inherent ethical and moral aspects which are often underexposed or disregarded in expositions of the circular economy.
} 
flow of waste and thus its recovery (Garrone et al. 2016; Graham-Rowe et al. 2014; Schanes et al. 2018). "Missing relations" (Burt et al. 2013) have received attention in social network research, which conceptualized them as "structural holes" (Burt 2004). The presence of structural holes indicates that parties in a network are disconnected and, as a result, cannot get access to pertinent information and knowledge held by other(s) (Hargadon and Sutton 1997). Building on different bodies of literature, i.e., sustainability, supply chain and network research, we conceptualize the holes that hamper the flow of waste between supply chain actors (and thus also its recovery) as 'circularity holes'. We identify the following distinguishing features of such holes, which in our view justify the novelty and relevance of this concept for the understanding of core barriers to waste recovery.

First, while the literature on structural holes has focused on the transfer of information and knowledge that are valuable for actors in networks, a circularity hole relates to supply chains and their discarded products. A circularity hole emerges because, for a variety of reasons, (1) its waste is not valued by the 'owner', who frequently prefers a discard rather than a transfer to others, and/or (2) potential recipients do not recognize the value of the waste and thus are not particularly interested in obtaining it. A further difference between circularity holes and structural holes originates from the (residual) value of the items that cannot be transferred and the accompanying moral dimensions. If an absence of connections leads to a structural hole, the information or knowledge that cannot be transferred to other actors is kept by its possessor and maintains its original value. In the case of a circularity hole, instead, the waste that does not flow to other supply chain actors, due to the lack of ties, will be discarded by the current owner. Consequently, its residual value will be gone, which has serious social and environmental implications.

In addition to conceptualizing structural holes, social network scholars have developed the complementary concept of "brokerage" (Burt 2004). Indeed, brokerage entails bridging structural holes, i.e., "joining previously unconnected parties to facilitate coordination, collaboration and the pursuit of common goals" (Lingo and O'Mahony 2010, p. 47). The broker is thus positioned between two or more actors who have no relationship with each other (Jang 2017) and connects them for the exchange of knowledge and information. The brokerage function has been extensively investigated in management literature. Previous studies have shown how different types of actors can become brokers and facilitate the creation of ties between disconnected organizations or individuals (Lingo and O'Mahony 2010; Obstfeld 2005; Stovel and Shaw 2012). While research has thus far mainly focused on brokers contributing to the achievement of business objectives, a few studies have provided insights into brokerage aimed at environmental and/or social value creation (Kaine and Josserand 2018; Manning and Roessler 2014; Saunders et al. 2017; Stadtler and Probst 2012). To date, however, scholars have not really paid attention to brokerage undertaken in supply chains and directed at saving items that have no value for the actors involved, as is typically the case for waste. The study of this type of broker, which we refer to as 'circularity broker', is important for ethical, societal and environmental reasons, as indicated above.

At the same time, waste is a very complex problem, and its solution is hampered by barriers on both the supply and the demand side, as noted particularly for the food supply chain (Garrone et al. 2016; Graham-Rowe et al. 2014; Schanes et al. 2018). Indeed, until recently, the complexity of the waste problem has inhibited dedicated steps towards solutions, except for very local and often temporary or incidental initiatives. This 'deadlock' seems to have been broken, to some extent, as a result of the emergence and spread of a particular kind of broker: the digital platform organization. Different types of platforms have been described in the literature (Gawer 2014; Thomas et al. 2014). This study focuses on digital "market intermediary" (Thomas et al. 2014) platforms as they are key to understanding circularity brokerage. These platforms have two core characteristics: (1) they "mediate[s] transactions" (McIntyre and Srinivasan 2017) between networks of supply- and demand-side users, and (2) they rely on digital technology to do so. As a key expression of the digitalization 'wave', this novel type of actor has disrupted all kinds of sectors (Parker et al. 2016) and can potentially bridge circularity holes by exploiting the opportunities offered by digital technology (Jin and Robey 1999). In particular, this type of brokerage allows for a much larger number of connections than 'traditional' brokerage, thanks to the network effects of digital technology and the ease with which new linkages can be made and administered.

Since these types of platform organizations have emerged only recently, research has not yet caught up with practice in terms of understanding how they work to bridge holes and recover waste. Inspired by the opportunity to contribute novel insights regarding waste platform organizations, the present study sheds light on this phenomenon by exploring, through an interpretive inductive theory building approach (Gioia et al. 2013; Shah and Corley 2006), how platform organizations foster food waste recovery. By focusing on platform organizations that have emerged in the past few years in the food supply chain, we were able to account in detail for the multiple brokerage roles that such organizations can take to close circularity holes and increase waste recovery.

Our work contributes to three main bodies of knowledge. First, we add to network research by providing insights into how platform organizations may engage in brokerage and contribute to bridging holes in the flow of waste. 
Second, our study contributes to the supply chain literature by exposing how new entrants that use digital technology may facilitate the development of sustainable, circular supply chains. Third, by advancing the understanding of how digital newcomers may help different constituents to reduce food waste, we shed light on key ethical and sustainability concerns faced by the food industry and thus contribute to the related literature.

This paper is structured as follows. First, we provide an overview of the theoretical lenses that informed our study. Specifically, we discuss insights from the literature on supply chains, networks and digital platforms. We also conceptualize circularity holes and the concomitant notion of a circularity broker. The development of these constructs was informed by our inductive research process, but we present them ahead of our results out of consideration for the reader. The subsequent section explains the method. This is followed by the presentation and analysis of the findings, which focus on fleshing out the multiple roles that waste platform organizations can take to bridge circularity holes in the supply chain. In the final sections, we discuss the implications of our research and the contributions to the literature, as well as limitations and possible avenues for future research.

\section{Theoretical Background}

\section{Food Waste Recovery and Supply Chains}

Over the last few years, scholars and practitioners have increasingly emphasized the "moral intensity" (cf. Jones 1991) of the waste issue, especially with respect to the magnitude and certainty of its negative consequences for the environment and for society. The existence of waste signals overproduction and a mismatch between supply and demand. This implies an inefficient use of scarce resources, which are spoiled instead of being preserved or employed productively (Gokarn and Kuthambalayan 2017). The natural environment is (often irreparably) affected by the disposal and landfilling of products and materials, which cause pollution of air, water and soil (Pagotto and Halog 2016; Papargyropoulou et al. 2014; Ribeiro et al. 2018). In addition, the particular case of food waste is seen as morally unacceptable (Ribeiro et al. 2018) in social terms: while onethird (approximately 1.3 billion tons) of the food produced for human consumption is spoiled every year (FAO 2017), one billion people globally suffer from food insecurity and malnutrition (Devin and Richards 2018). This shows that waste is also engendered by significant inefficiencies in the allocation of food, resulting in food being dumped instead of reaching those who need it the most. Accordingly, attention has increased for the possibilities for food waste recovery and for overcoming the barriers that hamper a good connection between supply and demand (see Table 1).

The growing awareness of the importance of waste recovery has led observers to rethink the traditional supply chain notion that focused on the sequence of activities from the production of the core product to its delivery to the final customer. This conceptualization indeed neglected waste and/ or saw it as an unavoidable side effect. Beamon (1998, p. 281), for example, defined the supply chain as "an integrated process wherein a number of various business entities (i.e., suppliers, manufacturers, distributors, and retailers) work together in an effort to: (1) acquire raw materials, (2) convert these raw materials into specified final products, and (3) deliver these final products to retailers" and to the end customers. This view of the supply chain has increasingly been defied by novel conceptualizations that highlight waste as an 'integral' issue to be tackled by all actors.

Relevant in this regard is the literature on "sustainable" (Pagell and Wu 2009; Seuring and Müller 2008) and "green" (Holt and Ghobadian 2009; Kumar et al. 2015; Rao and Holt 2005) supply chains, which refers to waste recovery as one of the practices that create environmental and/or social value (Chaabane et al. 2012; Linton et al. 2007; Pagell and Wu 2009). An emphasis on waste recovery is also found in research on "closed-loop" and "reverse" supply chains (Guide and Van Wassenhove 2009). This research stream initially considered waste recovery merely from a technical (Pagell and Wu 2009) and business perspective (Govindan et al. 2015) by investigating how to maximise the retrieval of economic value through the returns of used products and subsequent recovery activities, such as remanufacturing (Guide and Van Wassenhove 2006, 2009). In recent years, it has started to look at waste recovery from the perspective of environmental and/or social value creation as well (Faccio et al. 2014; Schenkel et al. 2015).

Closing the loop in the supply chain has recently been characterized as "an important backbone of the circular economy" (Lüdeke-Freund et al. 2019, p. 38), defined as "a regenerative system in which resource input and waste, emission and energy leakage are minimised by slowing, closing and narrowing material and energy loops" (Geissdoerfer et al. 2017, p. 759). This link between current supply chain and circular economy literatures (Geissdoerfer et al. 2018; Genovese et al. 2017; Lieder and Rashid 2016) indicates the growing attention assigned to waste recovery in the supply chain literature. It also points at the importance of adopting an inter-organizational supply chain perspective to foster a transition towards a circular economy (Lüdeke-Freund et al. 2019). The concept of the "circular supply chain" (Esposito et al. 2018; Fischer and Pascucci 2017; Genovese et al. 2017; Tse et al. 2016), proposed in recent studies, has contributed to focusing attention on the configuration and coordination of the supply chain for waste recovery (Geissdoerfer et al. 
Table 1 Main barriers to food waste recovery according to extent literature

\begin{tabular}{|c|c|}
\hline \multirow[t]{21}{*}{ Supply side } & Stigma related to food waste as sign of inefficiency \\
\hline & Underestimation of amounts of food waste/perception that it is not a big problem \\
\hline & Insufficient awareness of the social and environmental consequences of food waste \\
\hline & Consideration of waste disposal as an acceptable solution \\
\hline & Perception of food waste as inevitable and as socially acceptable \\
\hline & Perception that food waste is not the suppliers' (personal) responsibility \\
\hline & Lack of coordination with demand-side actors in the food supply chain \\
\hline & Complexity of managing the recovery of perishable goods in a short timeframe \\
\hline & Absence of clearly defined processes and activities for food waste recovery in the food \\
\hline & business, and seen as costing too much time, effort and money \\
\hline & Food recovery process in stores is not defined and approved at the corporate level \\
\hline & Absence of a food waste measurement and tracking system \\
\hline & Retailers' procedures of discarding products based on 'sell-by' dates and on appearance standards \\
\hline & Insufficient information for consumers about the meaning of 'best-before' labels \\
\hline & Unwillingness to sell products resulting from processing errors and packaging-related problems \\
\hline & Prioritization of financial over environmental considerations about food waste disposal/recovery \\
\hline & Limited quantities of edible waste which make recovery difficult in terms of logistics \\
\hline & Financial and reputational damage for food businesses due to health and safety issues arising from food donations \\
\hline & Misconception of liabilities deriving from food waste donations/transfer \\
\hline & Length of the donation process and additional costs, effort and logistics \\
\hline & Food donation is more expensive than its disposal \\
\hline \multirow[t]{9}{*}{ Demand side } & Consumers' unwillingness to buy 'imperfect' products and products close to the 'best-before' date \\
\hline & Consumers' misunderstanding of 'best before' labels \\
\hline & Absence of coordination with supply-side actors in the food supply chain \\
\hline & Retailers' procedures of rejecting products based on 'sell-by' dates and on appearance standards \\
\hline & Processing errors and problems in packaging not accepted by potential recipients \\
\hline & Charities' limited financial and time resources for collecting food \\
\hline & Mismatch between (potential) food donations and charities' needs \\
\hline & Charities' limited resources and time for carrying out administrative procedures related to food donations \\
\hline & Complexity of managing the recovery of perishable goods in a short timeframe \\
\hline
\end{tabular}

Sources Cicatiello et al. (2017), Filimonau and Gherbin (2017), Gaiani et al. (2018), Garrone et al. (2016), Hebrok and Boks (2017), Holweg et al. (2016), Mourad (2016), Muriana (2017), Richter and Bokelmann (2018), Sakaguchi et al. (2018), Schanes et al. (2018), Sert et al. (2018), Stancu et al. (2016), Stangherlin and de Barcellos (2018), and Thyberg and Tonjes (2016)

2018) as well as on the challenges and opportunities related to the implementation of this circularity.

In parallel with the increasing interest for waste in scholarly debates on supply chains, its meaning has been extended over time. In an older definition of the United Nations (1997), waste entailed "materials that are not prime products (that is, products produced for the market) for which the generator has no further use in terms of his/her own purposes of production, transformation or consumption, and of which he/she wants to dispose". Especially proponents of the circular economy have extended this definition (e.g., Gokarn and Kuthambalayan 2017) to also include products manufactured for the market but that are not sold, not consumed, or are at the end of their lifecycle(s). This more inclusive conceptualization reflects a circular approach to waste, grounded in the "waste-as-food" principle (Murray et al. 2017), which posits that waste describes a relative, not an absolute condition. This means that a good or a material may be labelled as 'waste' by one supply chain actor, while one or more other actors may see it as a potential 'resource' that can be valorised through reuse, redistribution, reparation, remanufacturing or recycling (Murray et al. 2017).

Waste recovery thus critically depends on the redesign of supply chain relationships (De La Fuente et al. 2008; Östlin et al. 2008) and on the development of novel forms of connections. These ties bring together supply chain constituents having goods and materials with no value to them, and actors, including "non-traditional" ones (Pagell and $\mathrm{Wu} 2009$ ), who are able to save goods and materials from landfilling by unleashing their value. More specifically, waste recovery relationships may, for example, consist of (1) novel buyer-supplier ties enabling the reverse flow of end-of-life products and components upstream for recycling or remanufacturing (Govindan et al. 2015; Guide and Van 
Wassenhove 2009); (2) connections between consumers to exchange used/surplus products (Kortmann and Piller 2016); or (3) links between businesses and new customer segments that avoid the disposal of products which can be of value to individuals or organizations. While these kinds of connections are fundamental for waste minimization, supply chains often feature 'holes' that hinder the transfer of waste and the recovery of its value.

\section{Networks for Waste Recovery: Structural Holes and Brokerage}

Social network theory provides a very useful lens for our study, because it draws attention to the absence of connections through the concept of "structural holes", denoting situations in which actors in a network "are unevenly connected with one another" (Burt 1992, p. 62) and are thus unable to exchange and share information (Burt 2007; Ellis 2003; Hargadon and Sutton 1997; Pollock et al. 2004). Structural holes may emerge as a result of the impossibility to establish direct ties, due to actors' prioritization of their own activities over those of others (Burt et al. 2013), or because parties fear opportunistic behaviour by their counterpart(s) (Pollock et al. 2004). As part of our inductive research process we came to identify, and rely on, insights from the network literature, to articulate missing connections in the supply chain that hinder the transfer of food waste and the recovery of its value. To indicate the difference with the structural holes studied to date, we conceptualize these missing ties as 'circularity holes'. In our view, the identification of circularity holes adds two further and important idiosyncratic features to the original notion put forward in social network research.

First, in the case of a structural hole, the information or knowledge that does not flow to other parties keeps its original value, as it stays with its original possessor. A circularity hole, instead, by hindering the flow of waste, causes resource disposal and thus a loss of its residual value, with negative environmental and social consequences. Second, in the case of structural holes, the information and knowledge that cannot be exchanged due to the absence of ties is valuable for the owner and for the potential receiver. The circularity hole, in contrast, exists because the value of a good is not recognized by its owner and/or by the potential receiver. This is often due to a lack of moral awareness of the implications or the ethical consequences of discarding the good as waste (Graham-Rowe et al. 2014). In the food supply chain, in particular, organizations and consumers are frequently resistant to transferring or receiving waste, and therefore not eager to engage in establishing connections for its recovery. For example, on the supply side, based on perceived costs and risks of recovery, manufacturers prefer to throw edible food waste in the landfill (Devin and Richards 2018; Filimonau and Gherbin 2017; Sakaguchi et al. 2018). On the demand side, standards for a product's maximum shelf-life, quality and aesthetics (Garrone et al. 2016; Ribeiro et al. 2018) as well as consumers' health concerns (e.g., about donated food) and misperceptions about the 'best-before-date' label (Schanes et al. 2018) lead to the rejection and discard of food that is still fit for human consumption.

In addition to structural holes, the network literature has identified brokerage, defined as "a mechanism "by which actors facilitate transactions between other actors lacking access to or trust in one another"' (Marsden 1982, p. 202; Obstfeld 2005, p. 104). The actor in a brokerage position, i.e., the broker, spans a structural hole by "building bridges" between individuals or organizations located "on opposites sides of the hole" (Burt et al. 2013, p. 531) to enable flows from one side to the other (Kirkels and Duysters 2010; Pollock et al. 2004; Stovel and Shaw 2012). The core function of the broker is to fill the gap between actors who have no ties with each other and allow them to get access to each other's information or knowledge (Hargadon and Sutton 1997). The broker, however, may not only bring together disconnected actors, but also "facilitat[e] new coordination" and relationships between already connected ones (Obstfeld 2005; Kirkels and Duysters 2010).

Early studies conceptualized the broker as 'the third who enjoys' ("tertius gaudens"), an intermediate actor that keeps parties separated in a conflictual context (Obstfeld 2005) in order to make the most out of its power and control (Borgatti and Li 2009; Choi and Wu 2009). By contrast, the last few years have seen the emergence of the broker as the "third who joins' ("tertius iungens") (Obstfeld 2005), an actor focused on "building and sustaining connections" (CollinsDogrul 2012, p. 992) by bringing parties together for the achievement of common goals, thus facilitating the creation and improvement of cooperative relationships (CollinsDogrul 2012; Obstfeld 2005; Quintane and Carnabuci 2016). The attention assigned to brokerage by recent publications in the field of ethics and sustainability has stemmed from the tertius iungens' view of the broker and has shed light on its importance for the achievement of environmental and/or social goals. Researchers highlight that the role of brokers is multifaceted and complex, and "goes beyond simply matchmaking between different actors and providing bridging ties" (Stadtler and Probst 2012, p. 33). This means that the context also matters.

To illustrate, recent studies focus on brokerage in the field of cross-sector partnerships. In particular, Stadtler and Probst (2012) showed how United Nations agencies and nongovernmental organizations (NGOs), acting as brokers, can foster partnerships for development. Manning and Roessler (2014) investigated how collaboration is facilitated by individuals acting from within and/or outside the partnering organizations. Hence, in a cross-sector partnership setting, a broker organization may play three main roles: as convener, 
mediator or learning catalyst (Stadtler and Probst 2012). An individual broker may take initiating and supporting roles (Manning and Roessler 2014). More recently, a supply chain perspective was taken by Saunders et al. (2017, p. 2), who discussed different brokerage exchange types based on the position of the focal firm for the "development, adoption and diffusion of sustainability initiatives". In addition, Kaine and Josserand (2018) explored how brokerage of grassroots organizations may help improve labour conditions in global supply chains. They also discussed different roles, including educating, organizing, supporting, collective action, whistleblowing and documenting.

This recent work has generated knowledge about brokerage for sustainability and ways to study it, thus providing a good starting point for further research. Notably, while the supply chains studied had sustainable sourcing as the final goal, the brokerage roles that were examined focused on the development, diffusion and adoption of initiatives fostering sustainable production among the suppliers (Saunders et al. 2017) or on the improvement of the governance and implementation of labour standards (Kaine and Josserand 2018). However, the waste problem affecting supply chains, and the 'who' and 'what' of brokerage aimed at circularity holes, have not really received research attention. The supply chain literature has highlighted how the flow of goods, specifically those that are considered to be waste by the 'owners', is at the heart of a sustainable and circular supply chain but, given the many barriers to recovery, the task of brokers in this context is both valuable and highly complex.

In order to distinguish a specific type of broker, which bridges circularity holes and facilitates flows of waste for recovery between actors along the supply chain, we employ the construct of a 'circularity broker'. In line with the description of circularity holes, we conceptualize the circularity broker as positioned along a supply chain and connecting actors with products or materials that have no value to them, on one side, with other actors that can use those products or materials for their own consumption or as inputs for their activities, on the other side. The circularity broker may bring together disconnected parties or link actors who are already tied to one another for certain supply chain activities but are disconnected for the transfer of waste. For example, an apparel retailer and its consumers may already have a connection to enable the transfer of clothing items from the retailer to the consumers. At the same time, there can be a circularity hole waiting to be bridged by a broker when it comes to enabling the take-back of used clothes from the consumers to the retailer.

Scholars have indicated how different actors may become brokers to achieve positive environmental and social outcomes. These actors include, among others, individual employees (Manning and Roessler 2014), NGOs (Kaine and Josserand 2018) or governmental agencies (Stadtler and
Probst 2012). The recent digitalization wave has, however, introduced an entirely new type of actor engaging in brokerage: the digital platform organization. The type of brokerage undertaken by this novel actor may differ substantially from what current network and supply chain research has covered to date, and thus deserves further attention.

\section{Digital Platform Organizations as Circularity Brokers}

In the past decade, platform organizations have become increasingly popular; Parker et al. (2016) even referred to a "platform revolution". This diffusion has driven the belief among scholars and practitioners that any product and service can potentially be turned into a platform (Thomas et al. 2014). While the expanding body of literature on platforms uses a variety of terms with often different meanings, we focus here on "market intermediary" (Thomas et al. 2014) platforms that rely on digital technology. Scholars have conceptualized a market intermediary platform as an "interface" that "mediates transactions" of goods and services between supply- and demand-side actors (McIntyre and Srinivasan 2017), thus enabling a "marketplace" (Thomas et al. 2014).

As such, market intermediary platforms differ from the other two common types of platforms addressed by the literature, i.e., the product platform and the platform ecosystem. The former consists of elements and modular components that can be efficiently employed to develop an array of products. The latter comprises an underlying platform technology and accompanying standards (e.g., a video-game console) designed by the platform leader, as well as a set of platformspecific complementary assets (e.g., video games) offered by third parties (Gawer 2014; Jacobides et al. 2018; Kyprianou 2018; Thomas et al. 2014). Market intermediary platforms are characterized by network effects (Eisenmann et al. 2006; Rochet and Tirole 2003): the value of the platform for one group of users depends on the size of another group and the benefits grow the better the matches realized by the platform (Armstrong 2006; Eisenmann et al. 2006).

Due to the relatively recent emergence of the platform economy, research on digital market intermediary platforms is still at an early stage. Management scholars have studied market intermediary platforms mainly from a strategic management perspective, exploring how they grow (Thomas et al. 2014) and compete (Eisenmann et al. 2006; Zhu and Liu 2018). A burgeoning literature looks at market intermediary platforms in the sharing economy, to study their environmental and/or social dimensions (e.g., Acquier et al. 2017; Eckhardt and Bardhi 2015; Laurell and Sandstrom 2017; Murillo et al. 2017). There is, however, a lack of insight into the actions undertaken by market intermediary platforms that leverage the potential of digital technology to transform supply chains into circular ones. Indeed, the features inherent to the platforms' digital nature, such as the 
higher connectivity (Ojala et al. 2018) and the possibility for digital contents to be "stored, transmitted, processed, [...] displayed" and combined from different sources (Yoo et al. 2010, p. 726), suggest that platforms may perform activities to facilitate waste recovery in new ways.

Enabled by the digitalization wave, the market intermediary platform organization has emerged as a new entity that takes an innovative approach to waste recovery. Such organizations exploit the opportunities offered by digital technology to create a business model around the rescue of waste from the landfill. The lack of research attention for market intermediary platforms concentrating on food waste recovery, especially considering the ethical, environmental and social relevance of their activities, is puzzling. To the authors' knowledge, only Michelini et al. (2018) have to date examined food waste platforms, but they took a sharing economy perspective. Their paper uncovered and described several sharing approaches adopted by such organizations, encompassing "sharing for money", "sharing for charity" and "sharing for the community" models. Although such a perspective sheds light on food waste platforms, labelling them as engaged in 'sharing' poses two main challenges. First, it seems to conflict with mainstream definitions of the sharing economy, which restrict the concept to the provision of temporary access to an underutilized good by consumers to other consumers (Frenken and Schor 2017). Second, characterizing food waste platforms as 'sharing' brings in the question of whether they meet the sharing economy's social and economic promise (e.g., Acquier et al. 2017; Ciulli and Kolk 2019; Murillo et al. 2017). This debate, however, does not apply to many of the food waste platforms that have emerged in the last years. Thus, whereas some food waste platforms may potentially be perceived as representing the sharing economy, the phenomenon of digital food waste recovery brokerage as exercised by many such organizations seems to be much broader than sharing.

In sum, current literature informs the conceptualization of challenges and mechanisms that are specific to the context of waste recovery (i.e., circularity holes and circularity brokerage). When it comes to articulating exactly how circularity brokers such as digital platform organizations foster waste recovery, however, research has not yet caught up with practice. Our interpretive inductive theory-building study, which we carried out in the context of food waste recovery, serves to bridge part of this divide.

\section{Method}

\section{Overall Methodological Approach}

We followed an inductive interpretive theory building approach to data collection and analysis (Gioia et al. 2013;
Shah and Corley 2006). This approach is especially suitable for developing novel theoretical insights that are firmly rooted in practice (Langley and Abdallah 2011). Although it involves an initial consultation of existing literature, our methodology differs from more deductive procedures by purposefully suspending judgment about the literature's conclusions (Gioia et al. 2013), so that new and potentially contrasting insights can emerge from the data. This approach fitted our research problem very well, given the wide range of literatures that could potentially inform the actions undertaken by waste platform organizations to recover waste, combined with a general lack of conceptual and empirical attention for these organizations. As common for inductive approaches, our research scope evolved from a relatively broad focus on understanding the actions of waste platform organizations to foster waste recovery to zooming in on the brokering activities and associated roles of these organizations.

We saw it as crucial to consult actors actually managing and directing waste platforms, because their experiences and understandings are key for how these relatively small organizations operate. We treated our informants as "knowledgeable agents" (Gioia et al. 2013, p. 17). Our role as researchers was thus to rigorously gather and analyse data about these experiences and elevate insights that could be expressed in relation to current theory (Shah and Corley 2006). In line with the interpretive tradition, we relied on semi-structured interviews as our primary source of data (cf. Nag and Gioia 2012). We triangulated with data from secondary sources to increase data richness and trustworthiness.

\section{Data Sources and Sampling}

We selected the food industry as our research context and waste platform organizations in the food supply chain as our main units of analysis. Given the high relevance of the food waste issue for business and society, and in view of the barriers to food recovery explained before, the food industry can be seen as a particularly revelatory setting to learning how platform organizations foster waste recovery. We chose the founder/CEO or a top manager from food waste platforms as informants and accessed their experiences and views by means of semi-structured interviews. To inform our sampling decisions and, later on, for triangulation purposes, we also collected extensive data from organizations' websites, social media posts and news articles. Overall, we followed a similar sampling approach as Nag and Gioia (2012), who purposefully sampled practitioners from organizations in the metal casting industry to study how firms accomplish knowledge creation.

We proceeded though three main steps. In step one, we performed a broad internet search to get an overview of relevant platforms active at the time (June 2017). In step two, 
this initial pool of organizations was further refined through a new round of desk research and by applying theoretically motivated criteria (Lincoln and Guba 1985; Patton 1980). In step three, we approached informants from different organizations for interviews, with which we continued to a point where adding interviews did not appear to alter or enrich the emerging theory (Strauss and Corbin 1990).

\section{Step One}

Relevant platforms were identified based on four main criteria. First, in line with our selection of the food supply chain as the overall research context, only platforms focused on the exchange of food waste were selected. Second, only those platforms that facilitated the exchange of edible food waste for human consumption were included. Exchanging this type of waste is understood to be the most appropriate way of resolving the food waste issue, after waste prevention (Papargyropoulou et al. 2014). Third, platforms established less than 6 months before June 2017 were excluded, since informants from such early-stage organizations would likely lack knowledge and experience relevant to inform our research question. Fourth, to make sure that the targeted organizations were still active, those that did not have recent offers posted on their platform(s) were filtered out. Regarding the fourth aspect, the extent to which the platform was active could only be assessed for the publicly accessible platforms. For platforms where access was limited, we searched on the platform's website and in the media. 27 platforms fulfilled our early-stage sampling criteria.

\section{Step Two}

As the main objective of our study was to uncover new theoretical ideas and concepts, we further selected organizations with a particularly high potential for enabling the discovery of meaningful explanations (Firestone 1993) in the form of novel concepts. A maximum variation logic was followed to avoid limiting the scope of our theory development to single sub-groups of organizations. As our research objective was focused on uncovering the different ways in which platform organizations foster the recovery of food waste, we used the categorization of Michelini et al. (2018) to verify that our sample represented all stages in the supply chain. Our logic was that including this type of variation would help us detect a larger and richer set of activities. Specifically, we made sure that organizations from the following categories were included: Business-to-Business (B2B), focused on businesses at the supply and demand side; Business-to-Consumer (B2C), linking businesses with final customers; Business-to-NGO (B2NGO), matching businesses with charities; and $\mathrm{C} 2 \mathrm{C}$ platforms, which connect consumers with edible food waste with consumers who are interested in getting it.

\section{Step Three}

Our final assessment regarding the sample's adequacy was closely related to judgments about theoretical saturation, which denotes a research stage where the phenomenon of interest has been satisfactorily accounted for by the obtained data (Bowen 2008). More specifically, we aimed for theme saturation (cf. Bowen 2008; Hyde 2003), which occurs when a sufficiently rich and stable set of concepts has been uncovered. In our case, this stage was reached when additional data did not enhance or revise the uncovered themes in meaningful ways. In the end, the same themes were observable across several sources of data, across several organizations, and across at least two of the four different platform types, suggesting the presence of empirically meaningful and theoretically stable concepts. Table 2 provides a description of the specific organizations included in our sample.

\section{Data Collection and Analysis}

We collected data between June 2017 and March 2018 . Before and after conducting interviews, we gathered secondary data from the following sources: communications by the platform organizations through their publicly available websites (considered to reflect the voice of the organizations and the actors within them), posts published by platform organizations on their Facebook pages (also considered as attributable to the organizations' views) and articles from media sources (coded with a focus on quotes and other pieces of text attributable to the organizations in our sample). The timeframe covered by the secondary data stretched from 2016 to 2018 .

The interviews were conducted via Skype, and in English, except for MyFoody (Italian), Optimiam (French) and Yo No Desperdicio (Spanish). All interviews were conducted, recorded and transcribed by the first author, who masters all these relevant languages and was deeply familiar with the secondary material. The interviews lasted between 25 and $50 \mathrm{~min}$. We maintained a flexible and open interview style in order to identify topics that were key to the specific informant (Gioia et al. 2013). However, a small set of standard questions was asked to all interviewees to maintain a basic level of scope and consistency (see the "Appendix"). Moreover, the secondary data were used to engage informants in discussions about the actions they had taken to help the recovery of food waste (cf. Corley and Gioia 2004).

Our initial standard queries focused on the organizations' reasons for choosing digital technology to tackle the issue of food waste, their actions to facilitate connections between supply- and demand-side actors for the recovery of food waste, the challenges they faced in achieving their mission, and the changes they had made to their platforms and/or to their activities and strategies since they had been 


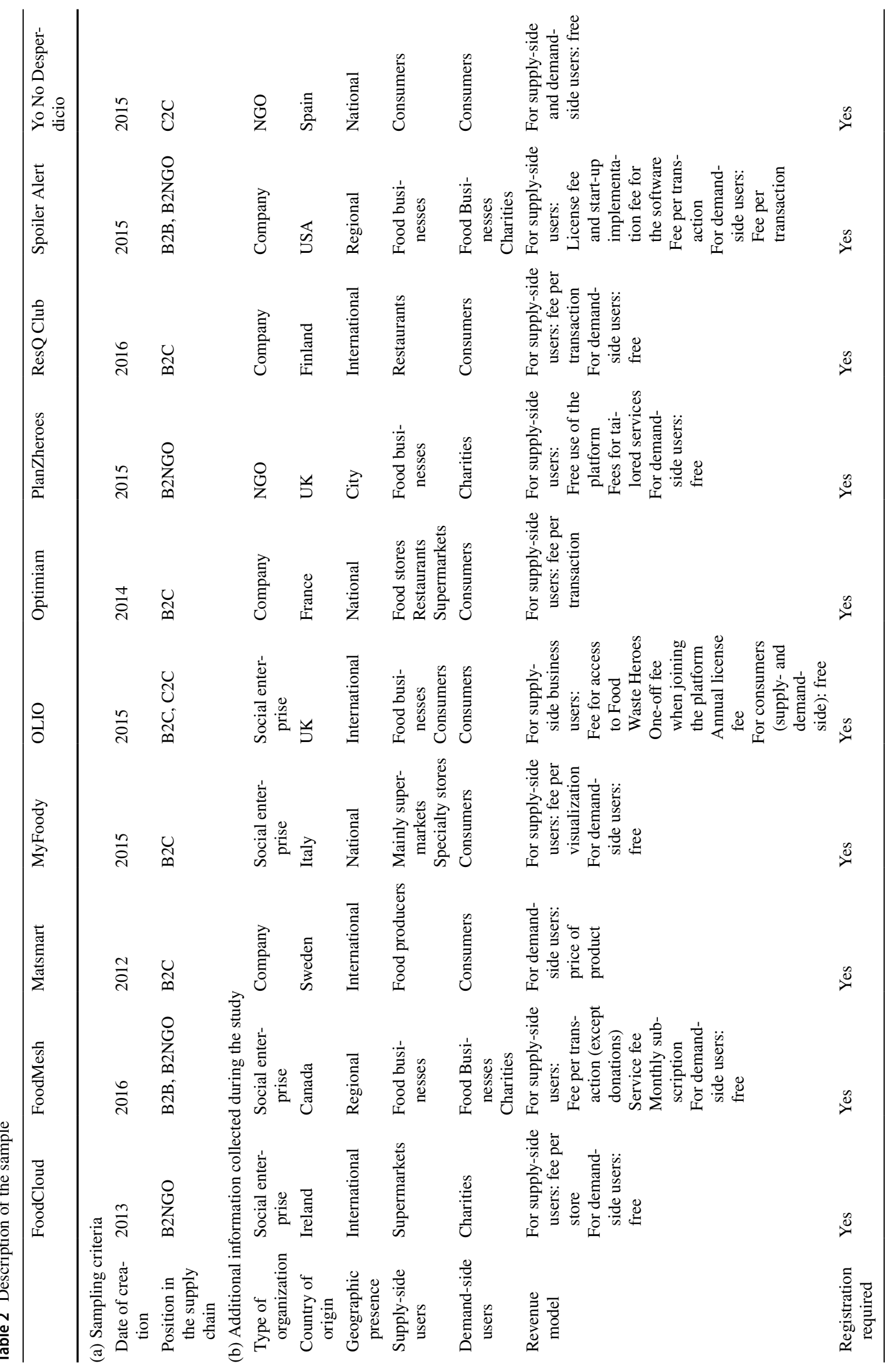


founded. In line with our focus on representing the reality experienced by our informants to the largest extent possible, we later expanded on these questions to reflect issues that emerged during the data collection (Glaser and Strauss 1967). For instance, after informants shared with us that they combined their platforms for food waste recovery with other businesses' food management systems, we included, where appropriate, questions that tapped more directly into this issue. In keeping with our focus on saturating the emerging concepts rather than the informants as such (cf. Bowen 2008), we opted for utilizing interviews with new informants rather than going back to 'old' informants when new themes were emerging. This having been said, the secondary data sources enabled us to search for relevant insights about the organizations also after the interviews had been conducted, which helped us to further enrich and verify some themes.

\section{Analytical Procedure}

The primary and secondary data were analysed inductively by means of open coding, in keeping with the "Gioia Methodology"2 (Gioia et al. 2013) and related approaches to

\footnotetext{
2 The method involves a systematic and rigorous approach to inductive data collection and analysis championed by researcher Dennis A. Gioia and colleagues over the course of more than 20 years. Although the method builds heavily on, and credits, traditional approaches to grounded theory development, it has increasingly been referred to as "The Gioia method" (e.g., Gioia et al. 2013; Langley and Abdallah 2011, p. 107). It should be noted that typical applications of the Gioia method are based on differing epistemological assumptions than typical applications of another popular approach to inductive theory building, namely the case study approach associated with Kathleen Eisenhardt and colleagues (Eisenhardt 1989; Langley and Abdallah 2011). While there can definitely be overlap regarding specific tools and techniques adhered to by researchers associating with the two approaches, the overarching goal of the research is typically different. Following Gioia, as we do in this paper, the focus is on capturing reality as understood and experienced by knowledgeable practitioners and on using this as a basis for developing novel and rather general concepts and theories. Following Eisenhardt, there is a greater emphasis on theory testing and uncovering facts that can explain variance across multiple cases (cf. Gehman et al. 2018, p. 292; Langley and Abdallah 2011, p. 109). The Gioia method thus focuses "less on the number or frequency of measureable occurrences" (Gioia et al. 2013 p. 16) than the Eisenhardt method, which observes frequencies to establish patterns of variance. While the Gioia method is more often than the Eisenhardt method associated with sampling of informants within a single organization, a common source of confusion seems to stem from the fact that it can (as in the present paper) also involve data collection across multiple organizations. An important distinguishing factor remains the underlying logic at play. For instance, Eisenhardt-type studies will typically sample several different organizations to maximize variation of specific outcomes or characteristics of interest, while minimizing others, to ensure that explanations for the differing outcomes or characteristics can be identified and replicated across cases. Sampling as part of a Gioia-type study can involve maximizing variation as well. However, this is not done for the purpose of explaining specific differences as such, but rather to increase the richness and relevance of the novel concepts that are being developed. Minimizing differences, such as zooming in on a
}

empirically grounded theory building and concept development (Gioia and Chittipeddi 1991; Gioia and Thomas 1996; Shah and Corley 2006; Strauss and Corbin 1990). The analysis started with attempts to understand and record core issues related to waste platform management. Emerging empirical insights were then increasingly confronted with theory as the analysis matured (e.g., Kjærgaard et al. 2011; Risi and Wickert 2017). In line with Risi and Wickert (2017, p. 624), literature "supported the research process, [but] did not determine our interpretation of the empirical data". For example, we identified social network research at a relatively early stage as a relevant theoretical lens because the data exhibited clear patterns of platform organizations being particularly concerned with addressing missing connections in the supply chains to enable food waste recovery. As we completed and further refined the coding of the whole data set, we increasingly zoomed in on how platforms secured such connections through a diverse set of roles. The analysis was continued until further reading and discussion of the data did not yield substantially new insights (cf. Sonenshein 2014) and until we had reached intersubjective agreement, i.e., consensus with respect to the interpretation and meaning of our data and codes (cf. Van Burg et al. 2014; Korstjens and Moser 2018).

More concretely regarding the analysis, we proceeded by means of (i) noting down a broad range of observations and terms that were highly reflective of the raw data, (ii) refining these initial categories into themes reflective of core elements in the data, and (iii) aggregating the themes to dimensions reflective of novel theoretical insights (Gioia et al. 2013). The initial efforts focused on registering any actions taken by platforms to trigger waste recovery. We scanned secondary data for preliminary insights that were further explored through the interviews. The first and secondary data were then coded, platform by platform, followed by the approach of "seeking similarities and differences" (Gioia et al. 2013, p. 20) among all the initial codes. For instance, we identified four first-order categories which had in common that they all illustrated the mobilization of volunteers undertaken by food waste platforms to bridge circularity

\section{Footnote 2 (continued)}

specific group or context by means of criteria-based sampling, can also be a Gioia-type strategy. Again, however, the logic is different: The guiding objective of such a sampling decision will typically be to enable focusing the theoretical development to a specific domain of interest, and not to isolate causal mechanisms that explain variation. The two approaches to theory development are both valid and useful (Gehman et al. 2018; Langley and Abdallah 2011), but awareness of their different origins and assumptions seems important in order to make judgments about the appropriateness as well as the outcomes of their applications. 
holes in the food supply chain. We coded these as all having to do with the theme of 'mobilizing volunteers'.

When relevant (such as with the terms 'framing' and 'cocreating'), theme labels were borrowed from current literature (cf. Reinecke and Ansari 2015). In other cases, when literature appeared to not have addressed what we found (e.g., in the case of "protecting"), we kept with our own formulations. When the themes started to replicate across different data sources and new rounds of coding did not lead to distinct changes, the similarities and differences approach was again used to further aggregate the themes. For example, the 'mobilizing volunteers' theme mentioned above was judged to concern the more general activity of 'mobilizing' to achieve waste recovery, as were the distinct but interrelated themes of 'mobilizing partners' and 'mobilizing stakeholders'. The analysis culminated with identification (and intersubjective agreement) of six core brokerage roles that platform organizations may take to bridge circularity holes in the food supply chain: connecting, informing, protecting, mobilizing, integrating and measuring. These roles can be seen at the right-hand side of Fig. 1, which offers an overall graphic representation of how we progressed from raw data to arrive at more general terms and theoretical concepts (Gioia et al. 2013).

\section{Multiple Researcher Roles and Other Steps to Secure Trustworthiness}

Interpretive data analysis must be able to provide "reasonable and plausible insight into a phenomenon such that a deeper understanding of the phenomenon can be gained" (Shah and Corley 2006, p. 1823). This means that quality judgments should predominantly focus on the steps taken to secure that the insights offered are pragmatically useful (Locke 2001) and representative of the context (Shah and Corley 2006). We took several steps to fulfil these criteria, for which the utilization of our different researcher roles was particularly fruitful. Specifically, we capitalized on our differing degrees of involvement in the data collection and analysis to balance empirical embeddedness with research independence (Gioia et al. 1994, 2010). The first author, for instance, achieved a relatively deep field immersion due to reading extensively about food waste management, managing the dialogue with all informants and taking the lead in interpreting the data through the open coding procedure. This helped secure that the insights we achieved were properly grounded in the focal context. The second author acted as a sparring partner, with special attention to securing a logical research direction, reviewing emerging themes, acting as a sounding board for ideas and asking critical questions. This helped increase the validity and reliability of the analysis (Corley and Gioia 2004; Lincoln and Guba 1985) and thus ensured meaningful interpretations of the focal context.

After the research had zoomed in on brokering roles, the first author discussed this overall direction with the third author without revealing the preliminary codes developed. The third author then independently coded the interview data with a focus on identifying roles, which resulted in a similar data structure as that of the first author, but with some omissions and additions as well as differences in interpretation. These differences were resolved through discussions among the researchers (cf. Saldaña 2013; Smaling 1992), where disagreements were worked out by engaging in reflexive discussions and going back to the primary and secondary data, leading to consensus regarding the coding of all the (sub-)roles. These efforts helped further ground the emerging theory in the data and served to audit (cf. Corley and Gioia 2004) whether saturation had been reached regarding the focal themes. In addition to investigator triangulation, we took several steps to secure the quality and trustworthiness of our research. Table 3 offers an overview of these steps, informed by Lincoln and Guba's (1985) wellknown criteria of credibility, transferability, dependability and confirmability.

\section{Findings}

The analysis of the data focused on exploring how platform organizations foster waste recovery in the food supply chain. It led to the identification of six brokerage roles undertaken by the food waste platforms: connecting, informing, protecting, mobilizing, integrating and measuring. Each of these roles is multifaceted and encompasses an array of sub-roles that the platforms may play to help close the 'holes' in the food supply chain. Figure 2 provides a simplified representation of how food waste platform organizations are situated between various actors at the supply side and the demand side, and how they can bridge circularity holes by drawing on one or more of the identified brokerage roles.

We will explain the roles and sub-roles consecutively below, providing more detailed information and representative quotes from the platforms included in our study. It should be noted that, due to the variation logic followed, we cover a range of different types of platforms (see the bottom part of Table 2). Some are businesses, others are social enterprises or NGOs, which indicates different priorities assigned to financial goal versus environmental/social mission in relation to waste recovery; there are also varieties in revenue models and geographical presences. In all cases, however, platforms require users to register with them and aim to have them regularly exchange food through the platform. 


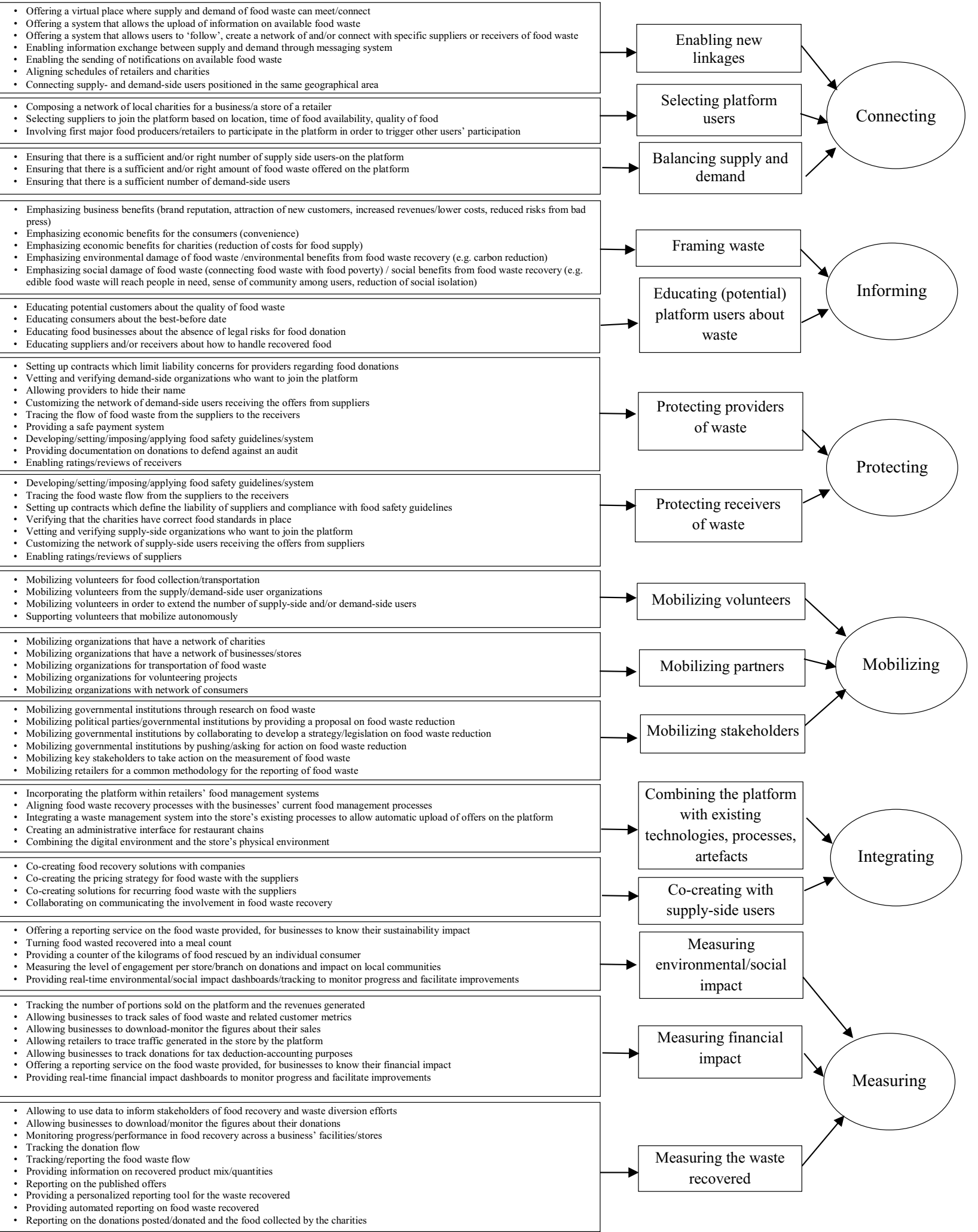

Fig. 1 Data structure 
Table 3 Steps to ensure trustworthiness

Trustworthiness criteria

Credibility (Do the findings represent plausible information drawn from the participants' original data and have steps been taken to secure correct interpretation of the participants' original views?)

Transferability (To which extent can the results be transferred to other contexts or settings with other respondents and still be considered informative and/or pragmatically useful?)

Dependability and confirmability (How stable are the findings, to which extent are conclusions and recommendations grounded in the data and not produced by the views and imaginations of researchers?)
Strategies pursued to satisfy criteria

Close engagement with the field

Triangulation of data and methods, emphasis on capturing world views of practitioners via both secondary document data and primary interview data

Sequential analysis of primary and secondary data before comparing insights across all data sources (cf. Nag and Gioia 2012)

Investigator triangulation (during coding, analysis and interpretation) and peer debriefing

Use of Nvivo 12.0 to ensure credible storage and management of data

Making sure to not only account for the "what" (i.e., describing organizations of interest and their choices) but also unpacking the "how" of the phenomenon (i.e., emphasising the multiple ways of doing related to bridging circularity holes, as information about this role repertoire can inform researchers and practitioners, also from different settings)

Providing sufficient information about the research context to make the uncovered roles and behaviours meaningful to an outsider, which enables readers' own judgments about transferability to contexts more familiar to them (cf. Korstjens and Moser 2018)

Purposive sampling (to control variation and ensure the emergence of stable and saturated core themes)

Interviews conducted in the language of informants when possible, transcriptions kept in the informant's own words and style

Separation of codes closely representing the data and higher-order themes to enable continuous verification of interpretations

Inclusion only of themes that could be supported with data from at least two informants and/or secondary sources of data (cf. Sonenshein 2014)

Reflexive discussions among researchers to achieve intersubjective agreement (i.e., alignment regarding the meaning of the data and the themes)

Audit of data collection, data management and analysis

Sources Adapted from Lincoln and Guba (1985), Shah and Corley (2006), and Korstjens and Moser (2018)

Fig. 2 Simplified representation of food waste platform organizations' position and brokerage roles

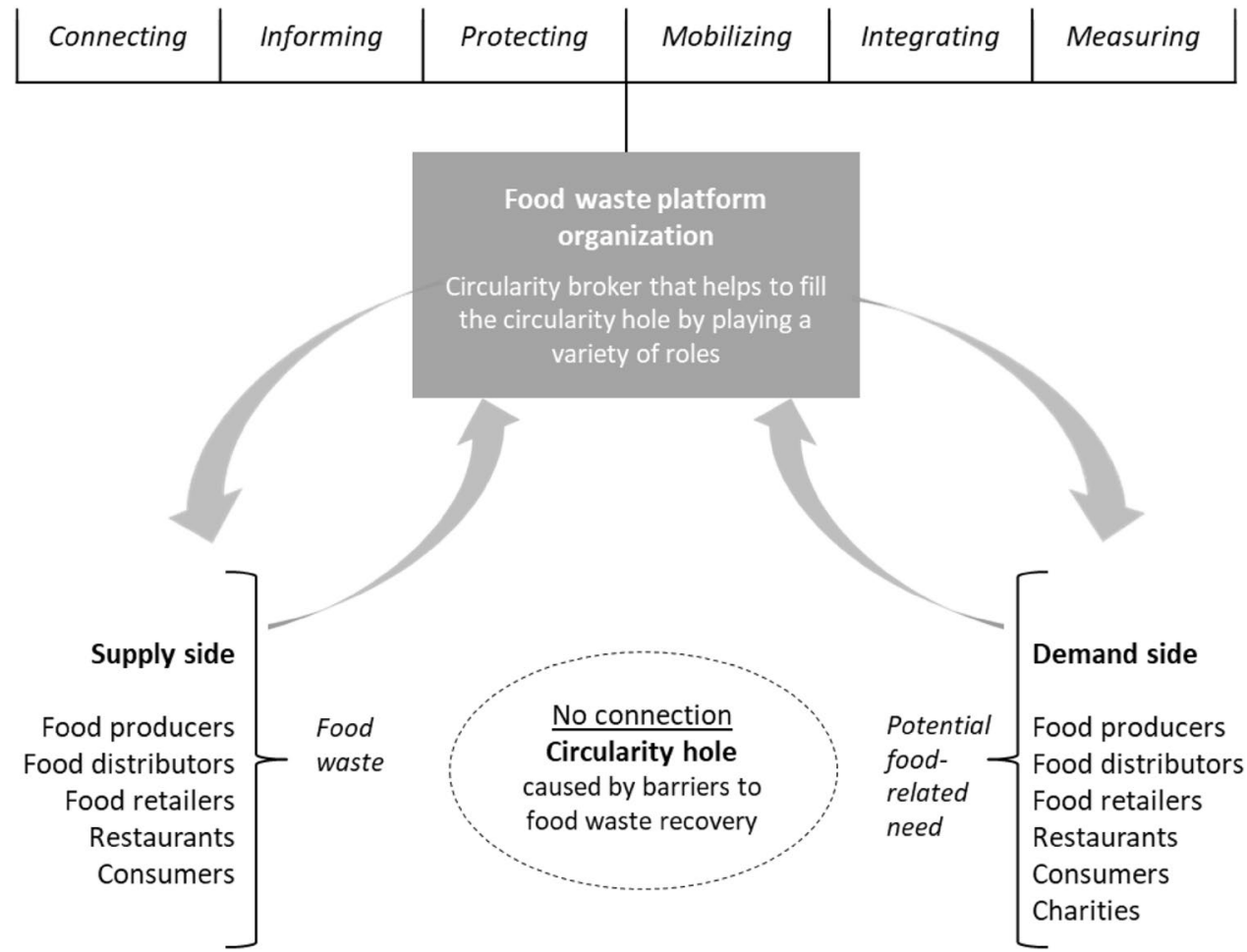


Table 4 The "connecting" role: Information and representative quotes

\begin{tabular}{|c|c|c|c|}
\hline Sub-roles & $\begin{array}{l}\text { Number } \\
\text { of plat- } \\
\text { forms }\end{array}$ & Types of platforms & Representative quotes \\
\hline Enabling new linkages & 10 & $\mathrm{~B} 2 \mathrm{C}, \mathrm{B} 2 \mathrm{NGO}, \mathrm{B} 2 \mathrm{~B}, \mathrm{C} 2 \mathrm{C}$ & $\begin{array}{l}\text { "Download the app and enter your location. You will be shown the } \\
\text { supermarkets closest to you, sorted according to the criterion of prox- } \\
\text { imity to your position." (MyFoody) } \\
\text { "Enter all the products details including photos and nutritional informa- } \\
\text { tion (as a photo is fine) to sell or donate. [...] When you're finished } \\
\text { entering all the information click on POST MY LISTING on the bot- } \\
\text { tom of the page. Email notifications will be } \\
\text { sent out at } 1 \text { pm each day, of any new listings created. [...] Organiza- } \\
\text { tions will contact you through the message function if they have a } \\
\text { question about your listing." (FoodMesh) }\end{array}$ \\
\hline Selecting platform users & 6 & $\mathrm{~B} 2 \mathrm{C}, \mathrm{B} 2 \mathrm{NGO}, \mathrm{B} 2 \mathrm{~B}, \mathrm{C} 2 \mathrm{C}$ & $\begin{array}{l}\text { "When a retailer states that it wants to enrol in the programme nation- } \\
\text { ally we receive a list of their stores and then we have a support team } \\
\text { [...] which works to try to find as many charities as possible that can } \\
\text { benefit from this surplus food and link them up to their local store." } \\
\text { (FoodCloud) } \\
\text { "In a first stage, we have targeted them [the businesses] based on their } \\
\text { location, which means in a very dense neighbourhood of Paris, where } \\
\text { there are a lot of shops and students and people who are connected } \\
\text { [to the internet], because the goal is that people can have access to a } \\
\text { promotion without having to travel } 4 \mathrm{~km} \text {." (Optimiam) }\end{array}$ \\
\hline Balancing supply and demand & 4 & $\mathrm{~B} 2 \mathrm{C}, \mathrm{B} 2 \mathrm{NGO}, \mathrm{C} 2 \mathrm{C}$ & $\begin{array}{l}\text { "If we see that we get to a certain level of portions getting purchased, so } \\
\text { that people purchase enough of the portions the restaurants publish, } \\
\text { the restaurant also gets engaged, because they get a positive feedback } \\
\text { that the service is working and people are coming to buy. So it's just } \\
\text { about managing the marketplace in balance so that we don't get too } \\
\text { many restaurants at once, because that way they will get bored as no- } \\
\text { one buys from them." (Res } Q \text { Club) } \\
\text { "We plan to convince several thousand businesses, so that our users are } \\
\text { more numerous and they have enough offers around them." (Opti- } \\
\text { miam) }\end{array}$ \\
\hline
\end{tabular}

\section{Circularity Brokerage Role 1: Connecting}

Connecting emerged as the core role played by all the platforms to tackle circularity holes in the food supply chain and thus to facilitate the recovery of food waste. The connecting role consists of linking organizations/individuals with a food surplus to those organizations/individuals willing and able to take it. This was explained effectively by the informant from FoodMesh, a B2B/B2NGO platform, when referring to the relationship between businesses and charities: "What I realized is that we don't have a food shortage problem, we have a connection problem". Connecting comprises three sub-roles: enabling new linkages, selecting platform users and balancing supply and demand, which we will explain consecutively below. Table 4 lists the number and type of platforms for which we found these sub-roles, and contains representative quotes.

\section{Enabling New Linkages}

All platform organizations performed the sub-role of enabling and creating new linkages. Thanks to digital technology, they were able to perform this sub-role by establishing a large number of connections. As stated by FoodCloud, a B2NGO platform:

...the idea was there is a business that has perfectly good food they are throwing out every day but there could be a charity literally around the corner who could benefit from this food, so we wanted to find a way through which we could easily connect each other...

By creating a virtual 'location' that supply chain actors with a food surplus could easily use for making it available so that those interested could easily find it, the food waste platforms aimed to enable the creation of new linkages. An aspect that was underlined by $\mathrm{B} 2 \mathrm{C}$ platforms such as Optimiam and ResQ Club is that they allowed retailers, restaurants and shops to create ties with new customers who were not in their existing network yet. Some platforms emphasized that connections were created especially between supply- and demand-side users based in the same location. For example, the B2C platforms MyFoody and Optimiam indicated that promotions were geo-localized, 
which helped a specific restaurant or retailer to attract nearby consumers.

All platforms except Matsmart offered suppliers the possibility to independently upload and offer surplus food on the platform and enabled demand-side users to visualize, reserve and/or buy it. In the case of FoodMesh, for example, every company would create its profile page to specify the type of food generally offered. A demand-side actor could look at these profile pages and decide to 'follow' specific suppliers and thus be notified every time a food waste offer was posted. One of the B2NGO platforms, FoodCloud, fostered the connection between supermarkets and charities by identifying, together with them, the day and time of the week on which the charity could expect to be notified about the supermarket's available food waste. Charities are usually confronted with a shortage of time and human resources while concurrently needing a reliable food supply. Thus, for them it was crucial to know in advance when they could access the food from the supermarkets, because a lack of coordination would hamper their ability to get it. Some platforms, such as Olio, YoNoDesperdicio, Spoiler Alert and FoodMesh, also facilitated connections by allowing users to communicate with each other through an online messaging system, in order to get additional information about the surplus food, arrange the pick-up and/or negotiate the price.

Matsmart played this sub-role in a slightly different way than other platform organizations. By getting ownership of the products, Matsmart did not facilitate the direct interaction between suppliers and receivers of surplus food, but it indirectly enabled new interactions, as food that could not be sold through the manufacturers' traditional channels was exposed on the platform, so that it could be found by an interested party.

\section{Selecting Platform Users}

For six platforms, positioned at all stages of the supply chain, connecting also meant actively searching and selecting organizations that would be suitable to join the platform as supply- and/or demand-side users. Some platforms (e.g., FoodCloud, Spoiler Alert) offered to create a network of recipient organizations around a specific business that had surplus food. Other platforms, instead, focused on selecting the organizations that had edible food waste to ensure that the offer was consistent with the demand. The presence on the platform of the right type of organizations was deemed crucial to successfully bridge the circularity holes in the food supply chain, as ResQ Club, a B2C platform, explained:

...of course the surplus they have and publish needs to be something that brings value to our end customers and that's the biggest thing that makes the whole thing work $[\ldots]$ So there of course we assess $[\ldots]$ what kind of food they have, where are they located, where our users are located compared to them and at what time they can publish their surplus and only then onboard the restaurants that we see can have their food sold through our platform.

We also found the case of a $\mathrm{B} 2 \mathrm{C} / \mathrm{C} 2 \mathrm{C}$ platform (OLIO) that put in much effort to make sure that a specific type of user (businesses) would offer surplus food on the platform, to thus encourage other types of users (consumers) to join the platform as respectively suppliers or receivers to optimise opportunities for a waste flow. It was noted to be very time consuming at the beginning to motivate individuals to "take the leap of faith" and join the platform. A key way to raise individuals' interest in the platform was to have a large number of offers on the platform; if new members saw that the platform hosted a significant amount of food, they would be more willing to either request or offer surplus food. Hence, to accelerate an increase in the number of individual members on the platform, OLIO involved retailers, because they could ensure a regular upload of a high-quality food supply on the platform. FoodMesh adopted a similar approach by involving renowned brands in order to motivate other businesses to also join the platform.

\section{Balancing Supply and Demand}

The third key sub-role performed by the food waste platforms consists of balancing the number of users on each side. Two B2C platforms (ResQ Club and Optimiam), a B2NGO platform (Plan Zheroes) and a B2C/C2C platform (OLIO) underlined that to be successful in bridging circularity holes in the food supply chain, it is crucial that supply/ offer and demand are in balance. ResQ Club stressed, in particular, the importance of having a sufficient demand for the restaurants that offer their food on the platform. Without this balance the restaurants would lose motivation for using the platform, with a high likelihood of abandoning the waste recovery initiative. Thus, to ensure a constant equilibrium on the platform, ResQ Club regularly monitored the networks on the supply and demand side and intervened where needed. A similar commitment was highlighted by Optimiam.

Some platforms noted to experience more challenges in involving actors on the supply side, while others faced this issue on the demand side. OLIO, for example, observed that the demand for food on its platform was exceptionally high, with $40 \%$ of food requested in less than one hour, while the involvement of users on the supply side was lower and slower. The platforms therefore emphasized to work on the 'weakest' side to ensure that there was sufficient demand for the available offer and sufficient offer for the demand. 
Table 5 The "informing" role: Information and representative quotes

\begin{tabular}{|c|c|c|c|}
\hline Sub-roles & $\begin{array}{l}\text { Number of plat- } \\
\text { forms }\end{array}$ & Types of platforms & Representative quotes \\
\hline Framing waste & 10 & $\mathrm{~B} 2 \mathrm{C}, \mathrm{B} 2 \mathrm{NGO}, \mathrm{B} 2 \mathrm{~B}, \mathrm{C} 2 \mathrm{C}$ & $\begin{array}{l}\text { "DO GOOD, RESCUE FOOD. The best way } \\
\text { to enjoy tasty restaurant food while saving } \\
\text { money, time, and the planet." (ResQ Club) } \\
\text { "1.300 million tons of food end up in the trash } \\
\text { [globally], of which } 7.7 \text { million in Spain. The } \\
\text { waste of food has serious social, environmen- } \\
\text { tal and economic consequences. Therefore a } \\
\text { greater effort must be made so that wasting } \\
\text { food is a thing of the past." (YoNoDesperdicio) }\end{array}$ \\
\hline $\begin{array}{l}\text { Educating (potential) platform } \\
\text { users about waste }\end{array}$ & 6 & $\mathrm{~B} 2 \mathrm{C}, \mathrm{B} 2 \mathrm{NGO}, \mathrm{B} 2 \mathrm{~B}, \mathrm{C} 2 \mathrm{C}$ & $\begin{array}{l}\text { "We hear from a lot of food businesses and } \\
\text { farms that are worried about the legal liabili- } \\
\text { ties of donating food and wonder, 'Am I liable } \\
\text { for donating food?' We're here to relieve these } \\
\text { concerns and spread word about the Federal } \\
\text { Bill Emerson Good Samaritan Food Donation } \\
\text { Act, which provides liability protection for } \\
\text { food donations made in good faith." (Spoiler } \\
\text { Alert) } \\
\text { "It is excellent to eat food even if the best before } \\
\text { date is close or has passed. Matsmart wants to } \\
\text { reduce food waste by increasing knowledge of } \\
\text { date labelling." (Matsmart) }\end{array}$ \\
\hline
\end{tabular}

\section{Circularity Brokerage Role 2: Informing}

According to the platform organizations, lack of information, misinformation and misbeliefs about food waste and waste recovery are among the key factors deterring supply chain constituents from connecting with one another to save edible food from the landfill. Thus, in order to help close circularity holes and encourage new linkages for the flow of food waste, all the platforms took an informing role, which comprises two possible sub-roles, i.e., framing waste and educating (potential) platform users about waste (see Table 5).

\section{Framing Waste}

All the platforms 'framed' the food waste (recovery) to shape supply and demand actors' perceptions and thus convince them to connect and bring about waste flows. They would engage in framing the recovery of food waste to supply chain players by underlining and constructing its economic, environmental and/or social meaning. It emerged from our findings that the choice of the frame often depended on the type of actor the platforms aimed to connect with: for example, whether the interlocutors were positioned on the demand or on the supply side; whether they were the sustainability managers or the board managers of a company; and/or whether they showed specific sensitivity for environmental, social and/or economic arguments.
We found that food waste platforms very often engaged in economic framing. For example, in order to trigger retailers to offer their edible food waste instead of discarding it, FoodCloud assigned an economic meaning to food waste recovery by using the frame of "reduction in waste disposal costs" and "positive brand sentiment". Similarly, FoodMesh underlined that food waste recovery would allow businesses to "decrease [their] disposal and spoilage fees", while Spoiler Alert referred to waste reduction as "an opportunity to impact the bottom line" and to "identify new revenue streams". MyFoody stressed that, by using the platform, a retailer could turn food waste into traffic to the point of sale, improve consumers' shopping experience, strengthen brand image and increase revenues. The economic framing was also adopted for the demand side. For example, ResQ Club, Optimiam, Matsmart and MyFoody emphasized to consumers that the purchase of edible food waste meant convenience and affordability. Likewise, FoodCloud promoted an economic interpretation of food waste recovery among charities, by highlighting the cost savings from getting access for free to food made available by retailers.

Environmental framing (e.g., highlighting the impact of food waste on carbon dioxide emissions) was very present on platforms' websites and apps, and used by several platforms in combination with an economic one. Matsmart, for example, noted that "our customers make an effort for the environment but also get more money in the wallet". Yet environmental framing does not seem to be the main type adopted in direct communications with target supply-side 
users by B2C platforms. They used it instead to seek the support for food waste recovery from specific actors, such as the sustainability manager of a company with food waste. The environmental frame was also employed, as explained by Optimiam, in conversations with some businesses that were particularly sensitive to environmental damage caused by food waste, but that were not (so) interested in the financial benefits of offering their surplus food because of the limited quantities that they had. Interestingly, the $\mathrm{C} 2 \mathrm{C}$ platforms OLIO and Yo No Desperdicio significantly relied on environmental framing of food waste vis-à-vis supply-side users.

Only a few platform organizations engaged in shaping potential users' interpretation of food waste (recovery) through social frames. This applied particularly to platforms connecting businesses with charities and by $\mathrm{C} 2 \mathrm{C}$ platforms. A case in point is PlanZheroes, which connected the problem of food waste with food poverty in the UK "to inspire food businesses to give their surplus food to those who need it". Another example is FoodCloud, which underlined exchanging food waste as "a win-win! Charities have access to a supply of fresh food and businesses can contribute to their community in a meaningful way". OLIO highlighted that its framing of food waste recovery as a social action benefiting the community was embraced by platform users, who expressed to OLIO that

what they loved the most was meeting a neighbour, feeling like they are part of the community, feeling empowered, feeling like they are making a difference and feeling like they are part of something. [...] What is powerful about OLIO is that it helps reduce social isolation, it also helps to increase social cohesion because different people from different classes and different backgrounds and different ethnicities are mixing to share food.

\section{Educating (Potential) Platform Users About Waste}

Six platform organizations, across all stages of the supply chain, referred to the need to 'educate' supply chain actors concerning food waste. This education has as specific goal to remove pre-existing beliefs of the actors on one or both sides of the hole with respect to food waste. FoodMesh, a B2B/B2NGO platform, and Matsmart, a B2C platform, mentioned their efforts to educate supply chain actors on the demand side in relation to the edibility of surplus food. Swedish consumers, for example, were said to have limited knowledge of the meaning of "best-before date" and of the difference between "best-before date" and "expiry date". This leads consumers to believe that food approaching or passing the best-before date is not edible anymore and, as a consequence, they refuse to purchase and eat it. Matsmart explained that it was trying to 'educate' consumers about the difference between best-before date and expiry date. Yo No Desperdicio put a similar emphasis on the expiration date, but then vis-à-vis Spanish consumers. And FoodMesh referred to the educating role toward target demand-side users' group, as

there is a big stigma [...] They think that because it's rejected is not good food but I said 'no it's great food, it just has the wrong label, there are reasons why this food is going to waste and it's not because it is not edible or good'. So I have to really convince purchasers, like catering companies and hotel chains that this is quality stuff.

Along the same line, FoodCloud mentioned its educational work on the demand side, focused on convincing charities that it was "perfectly good food", as well as on the supply side "to demonstrate to business that they could very easily support their local community by redistributing it". FoodMesh also referred to its educating sub-role undertaken on the supply side, to tackle businesses' belief that they would risk to be sued if they gave their surplus food to charities. FoodMesh in particular made potential suppliers aware of the "Food Donor Encouragement Act that protects food donors from liability for damages caused by donations of apparently wholesome food that they donate in good faith". Spoiler Alert likewise educated supply-side business users about the liability protection associated with food donations, as provided by the Bill Emerson Good Samaritan Food Donation Act. The platforms also engaged in educating users about how to handle the food that was supplied or received, by providing guidelines and information on how to proceed. For example, Plan Zheroes, a B2NGO platform, educated charities through guidelines and best practices about how to handle the edible food waste that they received.

\section{Circularity Brokerage Role 3: Protecting}

Seven platforms across the whole food supply chain indicated that, in order to bridge circularity holes, they needed to play the role of protecting supply and/or demand users from potential risks engendered by the other side of the platform (see Table 6). To help the flow of food waste, platform organizations felt they had to make users feel sufficiently safe to offer or collect food waste.

\section{Protecting Providers of Waste}

B2NGO platforms established a range of measures, including trainings and contracts, to reduce the (perceived) risks related to food donations. For example, FoodCloud aimed to protect supermarkets by setting the boundaries of their responsibility concerning the safety of the donated food and indicating that "the charity takes responsibility for the food 
Table 6 The "protecting" role: Information and representative quotes

\begin{tabular}{|c|c|c|c|}
\hline Sub-roles & $\begin{array}{l}\text { Number of plat- } \\
\text { forms }\end{array}$ & Types of platforms & Representative quotes \\
\hline Protecting providers of waste & 7 & $\mathrm{~B} 2 \mathrm{C}, \mathrm{B} 2 \mathrm{NGO}, \mathrm{B} 2 \mathrm{~B}, \mathrm{C} 2 \mathrm{C}$ & $\begin{array}{l}\text { "What are the food donors' liabilities? None, } \\
\text { because the charities have to sign our Charity } \\
\text { Agreement before they can add their profile } \\
\text { to our map and start to receive the donations. } \\
\text { Charities commit to take full responsibility } \\
\text { for the safety of the food once they receive it." } \\
\text { (PlanZheroes) } \\
\text { "Control who sees your listings, to protect your } \\
\text { brand"; "You can create a 'Verified Network' } \\
\text { group on the COMMUNITY page by check- } \\
\text { ing the box on the far right of each organiza- } \\
\text { tion you want in your Verified Network. This } \\
\text { way, when you post a new listing you can } \\
\text { choose your 'Verified Network' (on the listing } \\
\text { creation page), to have the new listing notifi- } \\
\text { cation email sent to" (FoodMesh) }\end{array}$ \\
\hline Protecting receivers of waste & 6 & $\mathrm{~B} 2 \mathrm{NGO}, \mathrm{B} 2 \mathrm{~B}, \mathrm{C} 2 \mathrm{C}$ & $\begin{array}{l}\text { "Donors must take all measures to ensure the } \\
\text { food is properly packed and safe to donate. } \\
\text { The businesses have also signed an agreement, } \\
\text { which establishes the terms of any food dona- } \\
\text { tion." (PlanZheroes) } \\
\text { "Why do you have user ratings? Sharing with } \\
\text { our neighbours is a lovely thing, but some- } \\
\text { times it is helpful to know if another user has } \\
\text { successfully shared in the past and was courte- } \\
\text { ous and timely. [...] Your rating should take } \\
\text { into account the other user's quality of com- } \\
\text { munication, timeliness for pickup and whether } \\
\text { the item was as advertised." (Olio) }\end{array}$ \\
\hline
\end{tabular}

from the point of collection and for ensuring that the food is treated in accordance with food safety legislation". Similarly, at PlanZheroes, when businesses and charities registered on the platform, they needed to electronically sign its legal agreement about the safe handling of the food and related liabilities. Protecting the providers of waste might also involve the prevention of risks from the type of demandside users, as we found that $\mathrm{B} 2 \mathrm{~B}$ and $\mathrm{B} 2 \mathrm{NGO}$ platforms vetted and verified the organizations that wanted to become demand-side users.

More 'radical' actions were also taken, such as hiding the food provider's name and/or 'customizing' a supply-side user's network to a limited and selected set of demand-side users. As the B2B/B2NGO platform FoodMesh underlined, "food surplus is a very sensitive topic" for food producers, and many of them believe it will endanger their brand(s) and/or reputation. Food manufacturers are often resistant to put their edible food waste 'on the market', as this shows their mistakes related, for example, to unsuccessful product launches or errors in the production process. To help reduce or even remove this barrier, Spoiler Alert allowed supplyside users to "hide [the] company name until the post is claimed". FoodMesh offered food companies the possibility to customize a network of potential receivers.
Furthermore, different from other food waste platforms where all other users of the platform could see it when one user would post its offer, FoodMesh gave food manufacturers several options. They could create a verified network of organizations and offer the food only to this selected group, they could notify all FoodMesh users or they could only target charities. As stated by FoodMesh, manufacturers could thus "control who sees [their] listings, to protect [their] brand", and if they did not want specific (types of) organizations to be notified about their offer they could exclude them. Other actions were also adopted by the platforms to protect supply-side users, such as providing a safe payment system (e.g., FoodMesh, Spoiler Alert and ResQ Club) and imposing food safety guidelines to those who received the edible food waste to minimize the risks for the providers. Olio and Yo No Desperdicio allowed the rating of receivers by the providers (and vice versa).

\section{Protecting Receivers of Waste}

Six platform organizations indicated on their website, with different degrees of strictness, which kinds of food could be offered on the platform. As explained by the B2NGO platform FoodCloud, food safety is one of the main challenges in 
food waste recovery. We found different approaches among platform organizations in this respect. FoodCloud protected demand-side users with regard to food safety by ensuring the "traceability of the food stock throughout the entire process" through access to data about the food donations from the supermarkets' scanners. This platform also required retailers (as well as charities) that wanted to join the platform to sign agreements stating their compliance with food safety guidelines. In addition, particularly to protect the final beneficiaries of the food, FoodCloud had an internal Food Safety Officer who supported and advised charities concerning food safety related issues. Furthermore, it asked the charities registered on the platform to "have a Food Safety Management system in place, which should also include food safety training/instruction". The B2C/C2C platform OLIO had as general rule that "if it's food you would eat, then it's okay for OLIO". To protect the demand side, i.e., businesses and NGOs, FoodMesh provided "Food Safety Guidelines" that indicated which food was not accepted food and specified risks related to specific food categories. Spoiler Alert underlined the requirements that had to be met by the suppliers, particularly with respect to prepared food.

FoodMesh mentioned the need to develop specific solutions to protect demand-side actors in other respects as well. It particularly noticed that charities worried about losing existing donors on the platform if offers were also accessible to other charities. FoodMesh thus developed software to ensure that charities would be offered the food of their 'own' donors first, and before it was offered to other charities. Similar to other platforms, PlanZheroes verified the businesses that wanted to join the platform to ensure that "the food is coming from a reputable source". A tool adopted by OLIO and Yo No Desperdicio to protect demand-side users instead involved peer reviews. After having exchanged edible food waste, individual users on the demand side could rate suppliers (and vice versa).

\section{Circularity Brokerage Role 4: Mobilizing}

Seven platform organizations noted that, to bridge the circularity holes in the food supply chain, it could be necessary to involve third parties that would help facilitate the creation of connections between supply- and demand-side actors. This 'mobilizing' role emerged as encompassing three main sub-roles, depending on the target group: mobilizing volunteers, mobilizing partners and mobilizing stakeholders (see Table 7).

\section{Mobilizing Volunteers}

Four platforms (OLIO, FoodCloud, PlanZheroes and Optimiam) were found to mobilize volunteers. The B2NGO FoodCloud was running a volunteer project called "Food Rescue Project" in which volunteers were in charge of transporting the food donations from the supermarkets to the charities. In order to help the transfer of food from the retailer to the charities, FoodCloud also mobilized employees of Tesco stores who were members of the volunteering programme "Tesco Community Champions". Optimiam had an "ambassador programme" that involved volunteers who would help expand the network of stores in their city or neighbourhood.

Particularly comprehensive and structured was OLIO's volunteer programme, which mobilized four types of volunteers: Ambassadors, Food Waste Heroes, City Champions and Market Makers. OLIO underlined the importance of Ambassadors to foster, among consumers, the willingness to connect with others for the exchange of food waste:

We have the honest, the passionate energy and enthusiasm of $[\ldots]$ an army of volunteers, we now have thirteen thousand volunteers, they are spreading the word about OLIO in their local community, with posters, with flyers, with letters, they speak at community events, they host community events, and that is really making a difference.

In addition, Food Waste Heroes enabled the flow of the edible food waste by collecting it from retailers, bars and restaurants, and bringing it to individual consumers' homes. The volunteers also added the food waste on OLIO's app and thus helped redistribute it this way as well. The other two categories of volunteers, City Champions and Market Makers, had an even greater responsibility. City Champions were in charge of fostering the adoption of OLIO in their city, and "raise awareness, drive sign-ups, generate local press, recruit local Ambassadors and establish Food Waste Heroes in their area". With an engagement of $30 \mathrm{~h}$ per week, Market Makers took "complete ownership for building a thriving OLIO food sharing community in their geographic area". OLIO supported the volunteers by developing a comprehensive set of materials that they could use to encourage businesses and individuals to give their edible food waste, fostering communications between volunteers, linking Food Waste Heroes to businesses, and offering guidance of OLIO's employees.

Interestingly, outside OLIO's core market, volunteers started to activate themselves independently around the platform. Upon these volunteers' request, OLIO made the platform available globally. Thus, while OLIO, due to resource constraints, could not facilitate the creation of linkages for the transfer and recovery of food waste in all 
Table 7 The "mobilizing" role: Information and representative quotes

\begin{tabular}{llll}
\hline Sub-roles & $\begin{array}{l}\text { Number } \\
\text { of plat- } \\
\text { forms }\end{array}$ & Types of platforms & Representative quotes \\
& &
\end{tabular}

Mobilizing volunteers $4 \quad$ B2C, B2NGO, C2C "We are supported by over 13,000 Ambassadors (grassroots volunteers) across the UK and the rest of the world. Our Ambassadors help grow OLIO in a variety of ways, including distributing letters to neighbours on their street, putting up informational posters, placing flyers in shops and cafes, role modelling food sharing behaviour, supporting new joiners, telling everyone they know about OLIO! [...] What do City Champions do? Our City Champions programme helps to grow OLIO in cities in the UK and around the world. The City Champion role is for those volunteers with the time, energy and passion to devote to making a significant step change in the adoption of OLIO in their area. As a City Champion you would be closely supported by OLIO's Head of Community and your main objective would be to launch and embed OLIO in your town or city over a 4-6 month period." (OLIO)

"How we work: When a business has surplus food to donate, they upload their information online. Nearby charities receive a notification of the available food and can claim the food online. Volunteers and transporters in the local area get involved by helping transport the food." (PlanZheroes)

B2C, B2NGO, B2B, C2C "FareShare was the perfect partner for FoodCloud in the UK. As the largest surplus food redistribution charity in the UK, they had the national scale and links with the UK voluntary sector necessary to recruit thousands of charities for the stores. FareShare is an existing partner of Tesco, and by us working together, we had the answer. Through shared values and complementary strengths, we could help Tesco to donate surplus food from its stores in the UK." (FoodCloud)

"At MyFoody, we started to collaborate with two important Italian retail chains, the UNES group in Milan and Turin, where we currently collaborate on 9 points of sale, and with UniCOOP Tirreno [...] Both UNES and COOP have decided to continue to trust us, expanding the collaboration with us on new stores" (MyFoody)

Mobilizing stakeholders $2 \quad$ B2NGO, C2C

"This week we have been at the Ministry of Agriculture, Fisheries, Food and Environment of Spain to talk about food waste, together with other organizations that are working on this subject [...]. Will the Strategy "More food, less waste" continue? How will the achievement of the SDG 12.3 be addressed? Will there be a law to regulate what to do with food surplus? Is it possible to make a big awareness campaign on food waste and on how we can reduce it? How is work going to be carried out with the different actors in the food supply chain? We are going to continue looking for answers and pending matters of the new Strategy" (YoNoDesperdicio)

"FoodCloud now sits on the European Union Platform for Food Loss and Waste. Through this work FoodCloud has been able to take some of the best practices happening at a European level and encourage the key stakeholders in Ireland to take action. Ward drew attention to the topic of measurement in 2017 when she addressed the National Food Waste Forum." (FoodCloud)

locations, groups of people concerned about food waste started to organize themselves autonomously to facilitate these connections, enabled by the platform organization.

\section{Mobilizing Partners}

In order to facilitate the creation of connections between supply- and demand-side actors in the food supply chain for the transfer of food waste, FoodCloud, FoodMesh, Matsmart, MyFoody, OLIO, PlanZheroes and Optimiam mobilized other organizations and established partnerships with them. Particularly interesting are the partnerships with organizations that gave the platforms access to additional supply- or demand-side users. For example, Matsmart partnered with Studentkassen, a company aiming to help students save money while contributing to a better environment. This partnership resulted in the development of a "food box that fits the student's wallet but at the same time does good for the environment", and gave Matsmart access to this important segment of demand-side users. Another example is FoodCloud's partnership with FareShare, UK's largest charity fighting hunger and food waste. Fareshare helped Foodcloud bridge the circularity holes for two main reasons: it had "the national scale and links with the UK 
voluntary sector necessary to recruit thousands of charities for the stores", and it had already established a food waste partnership with Tesco. Similarly, FoodCloud established a national partnership with Tesco and Lidl. The creation of a partnership with these retailers at the corporate level allowed FoodCloud to get access to their complete networks of stores as supply-side users. Likewise, MyFoody's partnership with two supermarket chains, Unes and UniCoop Tirreno, facilitated the expansion of the supply side through these supermarkets' multiple point of sales. Optimiam did the same through a partnership with retailers having several stores, such as Brioche Dorée. OLIO and Optimiam collaborated with local authorities and/or associations to help expand the network of platform users. A comparable approach was followed by FoodMesh when it partnered with large companies and municipalities.

To accelerate the expansion of its users' network, PlanZheroes instead partnered with Benefacto, a social enterprise providing volunteering opportunities to professionals. Benefacto helped PlanZheroes to involve groups of corporate volunteers who would contribute to "build links with both charities and food businesses". We also came across other types of partnerships that were aimed at facilitating the delivery of food waste. An example is FoodCloud's partnership with the Electricity Supply Board, which donated electric vehicles that the volunteers of the platform organization could use to bring food waste from the supermarkets to the charities.

\section{Mobilizing Stakeholders}

Two platform organizations, i.e., FoodCloud and YoNoDesperdicio, mobilized stakeholders not directly involved in the platform in order to develop measures that would accelerate the recovery of food waste. In particular, YoNoDesperdicio had undertaken different initiatives to push governmental institutions, such as Madrid's local government and political parties, to develop a strategy and legislation in favour of food waste recovery. And FoodCloud mobilized different actors to develop a common methodology for the measurement and reporting of food waste to facilitate its reduction and recovery.

\section{Circularity Brokerage Role 5: Integrating}

The findings indicate that almost all the platform organizations, in order to bridge circularity holes, needed to engage in establishing a direct relationship with (individual) supply chain actors located at one side of the hole. To enable and facilitate the flow of edible food waste along the supply chain, the platforms actively intervened to integrate new practices, solutions and tools in supply chain actors' logistics, production and/or marketing processes. 'Integrating' includes two sub-roles, i.e., combining the platform with existing technologies, processes and artefacts, and co-creating with supply-side users (see Table 8).

\section{Combining the Platform with Existing Technologies, Processes and Artefacts}

A key sub-role involves combining the platform with the existing food management practices and processes of the supply- and/or demand-side actors. To encourage businesses to make their food waste available on the platform and to do so regularly, six platform organizations identified the need to make the process of uploading as fast and easy as possible. As the B2NGO platform FoodCloud explained:

We also helped [the supermarkets] develop a process in the store that makes it easy, as easy as possible for them to donate the food. So the processes that we have developed will be very closely aligned to current processes that they have arranged.

The last version of FoodCloud's technology "is the first platform for surplus food redistribution that is fully integrated with a retailer's technology system". In the scanners used by Tesco employees for their core logistics, an option was added that allowed them to mark the products to be donated. This information was then automatically transmitted to FoodCloud's platform, and charities could be notified 'in real time' about the available food. MyFoody combined the platform with the in-store food management process even further. It integrated a "waste management system" that enabled retailers to identify the products near the expiry date through a dedicated barcode, to automatically upload them on MyFoody's platform and to delete the products from it when they passed through the cash register of the supermarket. Another example from a B2C platform is the creation by ResQ Club of an "administrative interface" for restaurant chains that allowed them to centrally monitor and manage all their restaurants and the posting of food by their headquarters. The B2B platforms FoodMesh and Spoiler Alert offered to suppliers of food waste an enterprise software system to facilitate the recovery of food waste, particularly for large businesses with multiple facilities or branches. This software could be integrated, on one side, with the suppliers' existing food management system and, on the other side, with the food waste platform.

The combination of the platform and supply-side actors' food management practices was also implemented within the stores. A core feature of the B2C platforms ResQ Club, MyFoody and Optimiam was that users needed to visit the physical store, restaurant and supermarket to collect the surplus food they had seen and/or purchased on the platform. For example, as illustrated by ResQ Club, "we also bring new customers to the restaurant, customers who 
Table 8 The "integrating" role: Information and representative quotes

\begin{tabular}{|c|c|c|c|}
\hline Sub-roles & $\begin{array}{l}\text { Number of plat- } \\
\text { forms }\end{array}$ & Types of platforms & Representative quotes \\
\hline $\begin{array}{l}\text { Combining the platform with existing tech- } \\
\text { nologies, processes and artefacts }\end{array}$ & 6 & $\mathrm{~B} 2 \mathrm{C}, \mathrm{B} 2 \mathrm{NGO}, \mathrm{B} 2 \mathrm{~B}$ & $\begin{array}{l}\text { "At offline level, we provide to the supermar- } \\
\text { kets a food management system in order to } \\
\text { better manage those products that are about to } \\
\text { expire and create special offers when products } \\
\text { approach the expiry date. Inside the stores, } \\
\text { we create shop-in-shop promotions with the } \\
\text { installation of co-branded no-waste areas } \\
\text { where products are collected in and sold to } \\
\text { supermarkets clients. [...] At the same time, } \\
\text { all the offers physically available at the super- } \\
\text { markets are spread out on MyFoody mobile } \\
\text { app." (MyFoody) } \\
\text { "To make it work for them we had to align with } \\
\text { their current processes and make as easy as } \\
\text { possible. In the UK we have integrated with } \\
\text { Tesco's [product] scanners. They can mark } \\
\text { food as 'donate', it goes up on to our system } \\
\text { and a local charity gets a notification." (Food- } \\
\text { Cloud) }\end{array}$ \\
\hline Co-creating with supply-side users & 8 & $\mathrm{~B} 2 \mathrm{C}, \mathrm{B} 2 \mathrm{NGO}, \mathrm{B} 2 \mathrm{~B}$ & $\begin{array}{l}\text { "Ugly fruit - odd-looking fruit - has become a } \\
\text { concept and awareness of how much is being } \\
\text { thrown unnecessarily. But what many may not } \\
\text { know is that the same phenomenon exists in } \\
\text { the candy world. Now Matsmart starts selling } \\
\text { sweets that have got the wrong shape at a } \\
\text { fraction of the price. This is done in collabo- } \\
\text { ration with the candy manufacturer Bubs." } \\
\text { (Matsmart) } \\
\text { "The offers have to be minimum - } 25 \% \text { in order } \\
\text { to be attractive for the customer and be vis- } \\
\text { ible on the app. You can decide to adjust the } \\
\text { discount \%." (Optimiam) }\end{array}$ \\
\hline
\end{tabular}

would otherwise cook at home that day. We bring people who would otherwise spend their money on grocery stores, to actually bring their consumption into that restaurant". Thus, consumers who would otherwise not visit a specific restaurant, in particular because of its relatively high prices, were encouraged to visit it because of the offers and discounts posted on the platform. The fact that these ties with consumers could extend beyond the online platform to the businesses' physical locations is a key way through which B2C platforms aimed to encourage businesses to offer their surplus food. Importantly, both MyFoody and Optimiam were permanently present in the supermarkets that were part of their network of users through co-branded corners, where the edible food waste available on the platforms was placed, and through stickers with the platform's logo on the food itself.

\section{Co-creating with Supply-Side Users}

Platform organizations with businesses as supply-side users engaged in inciting them to share their edible food waste by actively working on the development of solutions. Through the co-creating sub-role, the platform organizations actively integrated their knowledge, competences and requirements with those of their business users. The B2NGO platform FoodCloud collaborated with Tesco and charities on the development of the app to learn "how we could create the simplest solution to maximise the food donated". One of the B2C organizations interviewed, Matsmart, helped to create new solutions for integration into supply-side actors' food production/marketing, thus making edible food waste attractive to demand-side users and establishing new connections. For example, Matsmart supported the candy producer Bubs in saving "ugly" candies, which were thrown away due to production errors, by offering them on Matsmart's platform with a novel, attractive packaging. This consisted of packaging the ugly candies with Bubs' candy logo, to which a bandage was added to indicate that they tasted the same as the candies available in stores, but did not look exactly the same. According to Matsmart, this initiative helped to very quickly establish new connections with consumers to whom the ugly candies could be sold. 
Table 9 The "measuring" role: Information and representative quotes

\begin{tabular}{|c|c|c|c|}
\hline Sub-roles & $\begin{array}{l}\text { Number of } \\
\text { platforms }\end{array}$ & Types of platforms & Representative quotes \\
\hline Measuring environmental/social impact & 7 & $\mathrm{~B} 2 \mathrm{C}, \mathrm{B} 2 \mathrm{NGO}, \mathrm{B} 2 \mathrm{~B}, \mathrm{C} 2 \mathrm{C}$ & $\begin{array}{l}\text { "[Through Spoiler Alert] arm decision-makers with real-time } \\
\text { financial, environmental, and social impact dashboards to } \\
\text { monitor progress." (Spoiler Alert) } \\
\text { "Depending on the size of your business and your reporting } \\
\text { requirements (\# of meals saved, CO2 diverted, etc.), the } \\
\text { service is either free or we charge a small fee to cover our } \\
\text { operating costs." (Olio) }\end{array}$ \\
\hline Measuring financial impact & 5 & $\mathrm{~B} 2 \mathrm{C}, \mathrm{B} 2 \mathrm{~B}, \mathrm{~B} 2 \mathrm{NGO}$ & $\begin{array}{l}\text { [restaurants] "can track the number of portions they sell } \\
\text { through our platform and the revenue that the platform } \\
\text { generates for them." (Res } Q \text { Club) } \\
\text { "See the financial }[\ldots] \text { metrics of your company's diversion } \\
\text { efforts." (Spoiler Alert) }\end{array}$ \\
\hline Measuring the waste recovered & 6 & $\mathrm{~B} 2 \mathrm{C}, \mathrm{B} 2 \mathrm{NGO}, \mathrm{B} 2 \mathrm{~B}, \mathrm{C} 2 \mathrm{C}$ & $\begin{array}{l}\text { "Spoiler Alert makes it easy for businesses to track their } \\
\text { Spoiler Alert transactions. All transaction data is aggre- } \\
\text { gated on the Activity tab, accessible via the left-navigation } \\
\text { bar when logged into Spoiler Alert. All users from your } \\
\text { organization that are associated with your site in Spoiler } \\
\text { Alert can view transaction data, as well as sort, filter, and } \\
\text { export data from the Reports Dashboard". (Spoiler Alert) } \\
\text { "Each time you manage to give food to another person [...] } \\
\text { within your profile, tick the 'DELIVERED' box and those } \\
\text { kilos or grams will be added to your personal counter and to } \\
\text { the general one." "In your profile you can see the total Kg } \\
\text { [you have] shared." (YoNoDesperdicio) }\end{array}$ \\
\hline
\end{tabular}

Another example of a co-creating role is FoodMesh, which helped providers of food waste to find a solution for recurring food waste through the automatic publication on the platform. To simplify the recovery processes of supplyside users, Optimiam co-created the "Optibox", a surprise box which the retailers could fill with surplus food of a value of $10 €$, but that would be sold for a substantially lower price. MyFoody and PlanZheroes, among others, helped supplyside users to communicate their participation to the food waste recovery initiative, for example through social media. And platform organizations such as ResQClub and Optimiam were involved in the pricing of the products, by imposing a minimum discount and/or by helping businesses adjust their pricing to attract users on the demand side. The B2B platform Spoiler Alert highlighted the important role played by the "customer success team", which looked into the food waste data of the supply-side users in order to define the best food waste recovery solution.

\section{Circularity Brokerage Role 6: Measuring}

The last role undertaken by all the food waste platform organizations, except Matsmart, was measuring in ways specifically enabled by digital technology. Indeed, as the transfer of food waste was taking place through the platforms, they could collect data about the amount of food saved by each supply chain actor and/or the revenues made with the food waste sold. The platforms used these data to encourage supply- and demand-side actors to maintain and increase the linkages allowing the recovery of food waste, and to prevent the creation of food waste. As FoodCloud stated:

We're able to collect all sorts of data on all of the food which is donated, and the organizations it is donated to, which allows us to do things like provide full sourcing and measure the performance of the stores and charities.

We identified three main measuring sub-roles, i.e., measuring environmental/social impact, measuring financial impact and measuring the waste recovered (Table 9).

\section{Measuring Environmental/Social Impact}

Seven platforms positioned along the whole supply chain allowed supply-side actors to measure the amount of food waste they have saved through donations and/or discounted offers, in order to appraise the positive impact of their actions on the environment and society. We found various ways to provide information on the social and/or environmental impact. FoodMesh, for example, offered a "reporting" service that allowed companies to "know their sustainability impact"; similarly, MyFoody provided data that the supply-side users could use for their CSR communications. The user profile on Yo No Desperdicio's app had a "contador 
de comida" (meal counter) which showed the amount of food saved by individuals and thus their contribution to the food waste cause. FoodCloud measured the donations of retailers in terms of the "level of engagement" of each store with the platform and "the impact that they are having in their local community". Spoiler Alert provided "realtime [...] environmental and social impact dashboards" to supply-side users. Interestingly, PlanZheroes converted the number of kilos of food donated by each food business into an equivalent number of meals. The businesses could access and download these figures from their accounts, which allowed them to have a clear overview of the social impact in their communities.

\section{Measuring Financial Impact}

Five platform organizations, i.e., B2C (MyFoody, ResQ Club and Optimiam) and B2B/B2NGOs (FoodMesh and Spoiler Alert) platforms, provided supply chain actors with financial data about their food waste sold on the platform. FoodMesh allowed its supply-side users to track sales and related customer metrics. Restaurants joining ResQ Club could measure the number of portions sold on the platforms and the revenues made out of them. Spoiler Alert provided real-time financial impact dashboards, while Optimiam offered a monthly report of the offers published by retailers on the platform. Likewise, MyFoody enabled businesses on the supply side to "have a complete reporting" of their food waste recovery including, among others, data on "the number of sold products and promotion efficiency". In addition, in line with its integrating sub-role, MyFoody also allowed retailers to trace the traffic generated in the store by the platform.

\section{Measuring the Waste Recovered}

The measuring role also encompassed, for six waste platform organizations, the provision of supply-side business users with data on the waste recovered and on the waste flow, which they could use for different purposes, such as verifying whether everything was going according to plans, setting future waste recovery goals, identifying the causes of food waste or communicating the waste recovered to different stakeholders. FoodCloud, for example, gave retailers data on the quantity of food that was donated by the stores, which helped to identify problems in the food donation process and to address them promptly:

looking at the donation flow, we can monitor whether donations are not close to the expected pattern - this indicated that there could be a problem...So if there's any kind of internet connectivity issues, or delivery issues, it provides us with an early warning.
Similarly, PlanZheroes offered a "dashboard" to businesses with which they could monitor food donations. This was particularly valuable for businesses having multiple branches, as they could track what and how much each of them donated. Spoiler Alert gave businesses access to a "realtime reporting dashboard" that presented all the exchanges of food waste made by the business and, for each exchange, the type of food, its quantity and quality, the status of each exchange, the recipient, etc. Similarly, MyFoody enabled retailers to monitor "details of the most published and most sold products" and FoodMesh allowed supply-side users "to track where your food goes".

\section{Discussion}

This study aimed to explore how platform organizations foster waste recovery, by shedding light on the multiple brokerage roles that they can undertake to bridge circularity holes along the supply chain. In this section, we will discuss the roles that we found in relation to extant literature and highlight their novelty compared to prior research on brokerage. A novel trait observed about the roles performed by the platform organizations concerns their varying distance from the supply and demand sides of the circularity hole. In some cases, the platform is positioned "at the interface" (Edler and Yeow 2016) and the (sub-)role it performs is directed simultaneously and symmetrically at both sides of the circularity hole (e.g., enabling new linkages). In other cases, however, the (sub-)role (e.g., combining) targets only one of the sides. The holes that a particular circularity broker aims to address are usually characterized by constraints affecting one party more than another. As indicated in prior research (summarized in Table 1) and as shown in this study, there can be many reasons for the absence of ties for the transfer of food waste. Thus, to succeed in enabling the flow of waste between disconnected actors, the circularity broker must solve these hindrances by tailoring its interventions to the specific 'location(s)' in the supply chain where the problem rests.

Regarding the first role, i.e., 'connecting', this is central for all brokers at all stages of the supply chain. Indeed, as stated by Obstfeld (2005, p. 125), the core "tertius iungens function" is "to enable buyers and sellers to find one another". Our findings, however, also indicate how, thanks to digital technology, the nature and scope of the connecting role performed by platform organizations are substantially different from the ones undertaken by the 'offline' brokers explored to date (e.g., Fleming and Waguespack 2007; Manning and Roessler 2014; Pollock et al. 2004; Stadtler and Probst 2012). First, digital technology simplifies the broker's task of linking supply-side and demand-side actors in the supply chain, because it provides a virtual space where 
these actors can easily find one another and exchange relevant information in relation to the food to be recovered. Second, digital technology enables a much higher number of connections; actors with food waste have ample opportunities for its valorisation because they can easily attract many potential recipients/users. Moreover, as highlighted particularly by $\mathrm{B} 2 \mathrm{C}$ and $\mathrm{C} 2 \mathrm{C}$ platforms, digital technology links those that are located in the same area (through geolocalisation), allowing them to efficiently and effectively offer and exchange waste. This results in a greater magnitude of a broker's impact in a supply chain. As highlighted by our findings, the connecting potential of digital technology is tailored to suit the platform organizations' needs, with six among them emphasizing that they actively select supplyand/or demand-side actors. The digital platforms' connecting role may thus also entail actively defining who can be involved in supply and/or demand.

A key role played by all platform organizations is informing supply- and/or demand-side actors. Extant literature has mainly conceptualized the role of the broker as consisting of facilitating the "exchange" and "direct information flow between the brokered parties" (Quintane and Carnabuci 2016, p. 1347) and of filtering, interpreting and translating information from one side to the other (Manning and Roessler 2014). The informing role performed by the platform organizations in our study emerges as more articulated, as it entails producing information, importing it from external sources and communicating it to supply chain actors in order to convince both sides of the circularity hole to establish a connection for the exchange of waste. The identification of this role signals how waste is a particularly sensitive issue. It also suggests that the presence of circularity holes in the food supply chain largely originates from organizations' and individuals' perceptions of waste and waste recovery, often entailing moral unawareness and misconceptions. Previous research defined framing as "the purposeful communication efforts of leaders or managers in shaping the frames of interpretation of others in an organization, so that they collectively accept and support a change" (Cornelissen and Werner 2014, p. 198). Actors engaged in framing thus work to influence how other parties perceive what happens around them, either to strengthen existing interpretations (or frames) or to introduce new ones (Cornelissen and Werner 2014; Fiss and Zajac 2006). Bringing together this conceptualization and the findings of our study allows us to argue that, as circularity brokers, platform organizations engage in "purposeful communication efforts" to shape frames of supply and demand actors in the supply chain so that they "accept and support a change" (Cornelissen and Werner 2014, p. 198) in how waste is dealt with.

Studies on brokerage for sustainability underline that brokers need to "connect partners in favour of a common goal" (Stadtler and Probst 2012, p. 37), "mutual interest" or “common ground" (Manning and Roessler 2014). Our study instead suggests that the multifaceted nature and impact of waste requires platform organizations to adapt their framing based on the interests and profile of individual supply chain actors, by leveraging, to a different extent, environmental, social and/or economic interpretations of food waste (recovery). The brokers thus secure the bridging of circularity holes by tailoring the framing of waste recovery to the specific audience they target. In particular, by framing food waste and its recovery from an environmental and/or social perspective, the platforms help businesses and consumers to recognize food waste as an ethical issue, thus increasing their moral awareness (Rest 1986; Schwartz 2016). By stressing the negative environmental and social consequences of food waste and the positive impacts of its recovery, the platforms aim to reinforce the "perceived moral intensity" (Sonenshein 2007) of the issue among (potential) platform users and to thus prompt them to recover food waste. For those managers or consumers who seem less sensitive to ethical arguments, the platforms emphasize particularly an economic frame. Like Kaine and Josserand (2018)'s findings on brokers facilitating the implementation of labour standards, our research signals that platform organizations may engage in educating supply chain actors. In our context, however, educating does not address a general lack of knowledge, but specifically the misconceptions that organizations and individuals have about waste and that cause circularity holes to endure. Interestingly, B2NGO platform organizations work to 'dissolve' the ethical dilemmas that managers perceive with regard to donating food, by educating them about the absence of legal risks.

As to the third role, our study suggests that the broker may also need to mobilize third parties, i.e., volunteers, partner organizations and other stakeholders who can help, in different ways, to facilitate connections for the exchange of food waste. While the literature has largely depicted brokerage for sustainability as centred on just one individual actor (e.g., Stadtler and Probst 2012; Saunders et al. 2017), our findings resonate with Manning and Roessler (2014)'s statement that brokerage for sustainability is a "collective process". However, while Manning and Roessler (2014) illustrate this collective action as taking place in the same setting, the mobilizing role in our research highlights the presence of two types of settings, i.e., digital and physical. The platform needs to act, directly or indirectly, in both contexts in order to attain its waste recovery goals. While their brokerage mainly occurs in the digital environment, the bridging of circularity holes also requires interventions in the physical environment. For example, with the 'mobilizing volunteers' sub-role, some $\mathrm{B} 2 \mathrm{C}, \mathrm{B} 2 \mathrm{NGO}$ and $\mathrm{C} 2 \mathrm{C}$ platforms target in particular those consumers who already recognize food waste as an ethical issue and have internalized moral norms (Thøgersen and Ölander 2003), but lack a food waste 
recovery infrastructure that gives them the opportunity to act prosocially. The platforms leverage this moral recognition and provide the tools allowing these consumers to help people in need in their communities. By mobilizing, around their waste recovery target, volunteers acting 'in the field', digital platforms amplify and complement their brokerage, thus contributing to trigger waste flows in the supply chain.

Notable is also the 'protecting' role of platform organizations, which is new to brokerage research and addresses the complexity of the food waste issue and the ethical dilemmas related to recovery decisions. While recognizing the negative social and environmental consequences of food waste, managers perceive relevant risks of their business ensuing from food waste recovery. For example, for a manufacturer, indicating that it has waste (and particularly food waste) means revealing the presence of mistakes and inefficiencies in its value chain, such as production errors or unsuccessful marketing (Garrone et al. 2016). While digital platforms have the advantage of making an offer visible to a considerable array of potential recipients, this may raise concerns among suppliers that are keen to save their waste but do not want certain actors to know about these weaknesses. Concurrently, digital technology can also be highly effective in allowing supply chain actors to select, for every batch of waste, those platform users with whom they aim to establish a tie for waste recovery. Limiting the number of potential recipients of food waste seems inconsistent with a core assumption in platform literature, whereby "value to any given user largely depends on the number of users on the network's other side" (Eisenmann et al. 2006, p. 3). Our findings suggest, nevertheless, that circularity brokers might resort precisely to such a limiting role to resolve the ethical dilemma of suppliers. Another ethical dilemma perceived by managers of firms with food waste relates to the legal risks and harm for their business' reputation which may result from food donations. B2NGO food waste platforms' protecting role also entails activities to solve this dilemma, such as contracts that limit the liability of organizations that donate food. Hence, to bridge circularity holes, a platform organization may need to address suppliers' ethical dilemmas, by giving them the possibility to find suitable connections for their waste while, at the same time, granting them the control over the kind and number of demand-side users that can access their offer and/or limiting the legal liabilities tied to food donations.

The fifth role, 'integration', typically performed 'on one side' of the circularity hole, resonates with the supply chain literature. Flynn et al. (2010, p. 59), for example, define supply chain integration as "the degree to which a manufacturer partners with its external partners to structure inter-organizational strategies, practices and processes into collaborative, synchronized processes". Yet, while existing work focuses on supplier or customer integration, our study suggests the importance of the integration with the digital broker, i.e., the platform organization, to maximize waste recovery. We found that digital technology is crucial for enabling the circularity brokers' integrating role, and particularly the combining sub-role, undertaken by several platforms with businesses on the supply side. Incorporating the platform within firms' existing logistics devices and synchronizing the upload of waste on the platform with their food management processes is key to closing circularity holes. Indeed, it allows an efficient and effective information flow about waste and can, as a consequence, tackle firms' concerns about a timeconsuming waste recovery process. Furthermore, combining the digital platform with the physical environment of the supply-side actors increases the creation of new linkages for waste recovery, as it raises customers' attention and awareness about waste and simplifies their search for products they have seen on the platform. The sub-role 'co-creating', absent in existing literature, is especially related to the inherent nature of waste, a resource that has no value for supply chain actors. In order to ensure that waste is recovered, the circularity broker may need to actively engage in enhancing its value through "co-creation" (cf. Ranjan and Read 2016) with supply-side actors.

Prior research on brokerage has mainly focused on the stage of creating linkages, not on the role of the broker in maintaining, intensifying and expanding these connections. The only exception seems to be Stadtler and Probst (2012, p. 32), who paid attention to the role of broker organizations, in the context of public-private partnerships (PPPs), in helping to "monitor, review and evaluate PPPs over time". In keeping with corporate sustainability researchers, who have underlined the importance of a measurement system as "key component of any corporate sustainability initiative" (Searcy 2012, p. 240), our study shows how measuring is a key role for circularity brokers positioned at all stages of the supply chain. To ensure the recovery of all waste, the flow of saved food between supply chain actors needs to be regular and continuous over time. Extant literature has highlighted the importance of "feedback loops" (Schwartz 2016) of ethical decision making: the learning derived from observing the "actual consequences" (Hunt and Vitell 1986; Schwartz 2016) of one's decisions may impact future decision making. Measuring the social and environmental impact of the food saved from the landfill allows supply chain actors to observe the consequences of their waste recovery actions. This can keep them committed to their current recipients of food waste and motivated to create new connections for the further exchange of food waste.

Monitoring where they stand in relation to their own waste reduction/recovery targets also allows managers to obtain insight into the progress made and the financial benefits and opportunities tied to food waste recovery. Knox (2018) has highlighted how managers may perceive 
dilemmas in which the "ethical imperative" of honouring obligations to society (and the environment) "conflict[s] with the ethical imperative of honouring contractual obligations to the firm". Measuring environmental, social and financial impacts of food waste recovery helps to address such ethical dilemmas by showing that there is often no trade-off because food waste recovery has positive impacts for the society and the environment, as well as for the firm. Digital technology is fundamental for platform organizations to perform this measuring role, given that it allows them to track the food waste flows and collect all the relevant data, which they can then transfer to the supply chain actors.

\section{Conclusions}

In recent years, researchers and practitioners have increasingly paid attention to food waste, which is seen as highly unethical given its negative environmental and societal implications. The rise of circular-economy thinking (Esposito et al. 2018; Murray et al. 2017) has inspired ideas to redesign existing supply chains. A key principle of the circular economy, "waste-as-food" (Murray et al. 2017), suggests that waste recovery is critically dependent on the creation of new ties between supply chain actors to start exchanging goods at risk of becoming waste. However, the fact that food waste still represents one-third of the food annually produced in the world indicates the persistence of 'circularity holes' along the food supply chain. A new type of actor, the digital platform organization, has recently entered the food and other supply chains, to foster waste recovery by bridging circularity holes. While publications have explored brokerage for sustainability (Kaine and Josserand 2018; Manning and Roessler 2014; Saunders et al. 2017; Stadtler and Probst 2012), they have overlooked how digital technology and a waste recovery goal shape how this function unfolds in a supply chain context. This paper explored how platform organizations foster waste recovery, by shedding light on the brokerage roles they play in the food supply chain. Through the adoption of an interpretative inductive research design, we identified six roles played by platform organizations to bridge circularity holes in the food supply chain, i.e., connecting, informing, mobilizing, protecting, integrating and measuring. Our analysis shows that circularity brokerage is a multidimensional concept. We attribute this, in particular, to the complexity of the waste issue and to the instruments offered by digital technology. Below we will discuss the contributions of our study to the broader literature, the implications for practitioners and policymakers, limitations and recommendations for further research.

\section{Implications for Research and Practice}

This study makes three main contributions to the literature. First, it contributes to the literature on brokerage. By examining the brokerage performed by an underexplored but increasingly important actor, i.e., the digital platform organization, we shed light on how digital technology shapes the roles played by a broker. Furthermore, we provide insight into a specific type of brokerage, i.e., circularity brokerage, which has been overlooked by research thus far. In view of the novelty of the phenomenon, the Gioia methodology adopted in this study proved particularly valuable for unpacking the composite nature of circularity brokerage and for gaining in-depth insights into its different manifestations. Our research responds to the growing interest in the circular economy on the part of both scholars and practitioners by showing what brokerage entails when its ultimate goal is to drive the recovery of resources that would otherwise, for a variety of reasons be doomed for the landfill.

Second, and partly related, our work contributes to the circular supply chain literature. The conceptualization of the 'circularity hole' emphasises the lack of connections between supply chain actors and enables a better understanding of the factors hindering the development of circular supply chains. We also shed light on ways in which a newcomer that relies on digital technology may enter a supply chain and drive its shift towards a circular one, by bridging the holes that hinder waste recovery. Our finding that a circularity brokerage entails a variety of roles implies that bringing about change is complex and requires different responses and an array of activities to overcome the barriers to food waste recovery and realise circular supply chains.

Third, we add insights to existing publications about sustainability and ethics in the food industry. By focusing on a major environmental, economic and social issue for the food supply chain, i.e., food waste, we show how at least part of it can be addressed, and how platform organizations and digital technology can be crucial in this respect. Our research also demonstrates that new entrants, by undertaking different roles, may help incumbents to address the sustainabilityrelated struggles that they face.

Moreover, our study has implications for practitioners and policymakers. The identification of roles and sub-roles played by food waste platform organizations can help businesses with food waste to find promising avenues for collaboration with this novel actor to maximize food waste recovery. Furthermore, given the valuable complementary role of volunteers, organizations engaged in volunteering programmes could partner with food waste platforms to help them scale up and achieve their waste recovery goals. The findings also provide potential new entrants with a range of possible actions for food waste recovery. Moreover, platform organizations operating in other supply chains may draw 
inspiration from this study to assess which of these roles are most relevant to them, while technology companies can explore support options for the type of platforms that we investigated.

Based on our findings, policymakers might want to explore how they can support the roles undertaken by food waste platform organizations to increase the chances of closing circularity holes in food supply chains. For example, particularly local policymakers could back the platforms' framing sub-role by designing communication campaigns that underline the environmental, social and economic losses engendered by food waste, so as to drive citizen and business awareness of the issues at stake. It would also be possible to provide policy support for the platforms' educating sub-role, inter alia by intervening on the 'best-before' labels either through information initiatives or regulatory action. Another role that policymakers could facilitate is, for example, platforms' connecting role: economic incentives such as (higher) disposal taxes or tax benefits for waste recovery activities are likely to trigger businesses and consumers to embrace food waste recovery solutions.

\section{Limitations and Future Research}

This study provides insight into a new, fascinating type of organization that aims to play a key role in the food supply chain's transformation towards circularity. However, it also has limitations which hint at avenues for further investigation. Regarding the overall design of our study, the chosen inductive approach is highly valuable for developing novel insights that are firmly rooted in practice. While we have taken many steps to establish trustworthiness, it will remain a task for future research to further validate our findings by employing, for instance, theory testing designs. In addition, our paper examines a specific, very relevant supply chain. However, in this time of the "platform revolution" (Parker et al. 2016), platforms for waste recovery have recently emerged in other supply chains as well. Interesting examples include digital platforms for the recovery of clothing between consumers (e.g., the Next Closet) and B2B platforms that facilitate the recovery of construction waste (e.g., Pathway21). Further research could explore the roles that they have taken in order to assess similarities and differences across sectors and verify whether and how the roles identified in this study apply to other supply chains. In addition, as the present study showed the involvement of different actors around the food waste platforms, investigating these networks would be very interesting.

Furthermore, while the Gioia methodology was the most suitable to shed light on the novel phenomenon of digital platforms acting as circularity brokers and to uncover the richness of its manifestations, follow-up research with a different design might examine the factors behind the platforms' choice of their portfolio of roles. Such future studies can, through different research approaches and informed by our findings, develop variance-based models or advance and test formal propositions about when and why certain organizations come to rely on specific roles. A relevant research question in this respect is whether features inherent to the individual platforms, to the platform types and/or to the context predict which (sub-)roles platforms tend to play in order to recover waste. It would also be valuable to explore the impact, i.e., whether and how each of the (sub-)roles influence supply- and demand-side users' willingness to utilize the platform, the amount and frequency of food waste posted and acquired, as well as the financial sustainability of the platforms. Further studies might as well help to shed light on whether different portfolios of (sub-) roles are more effective at the different stage(s) of the supply chain. One could also examine these same outcomes from a design perspective, for example, to assess which platform elements foster or hinder willingness of consumers and business customers (and of their employees) to use the platforms.

Importantly, our study signalled that platforms venture to address some of the ethical dilemmas faced by organizations and consumers with regard to food waste. The complexity of the waste issue and the nature of the food waste platforms, which are sometimes social enterprises, hint at the possibility that they themselves may also be confronted with ethical dilemmas, including tensions between social/environmental and economic/financial objectives (Kannothra et al. 2018). Future studies might help to shed light on these dilemmas and on how they are addressed. It would also be interesting to obtain more insight into the factors triggering volunteers' willingness to mobilize around a food waste platform, as in the cases of Olio and PlanZheroes.

Another interesting avenue for further research concerns the internationalization of waste platform organizations. While many of the platforms explored in this study are still local/national (e.g., FoodMesh, MyFoody), some are starting or considering to operate across borders (e.g., Resq-Club, Matsmart, Olio). Building on initial literature on the internationalization of digital firms (e.g., Brouthers et al. 2016), one could study whether and how food waste platforms are affected by, and deal with, cross-country differences in regulation, awareness, attitudes and behaviours towards (food) waste. Future studies might also look into whether and how morally aware consumers may help the international upscaling of the platforms, considering that the internationalization of Olio, for example, was triggered by consumers concerned about food waste in foreign countries.

Moreover, our study focuses on food waste platforms located in developed countries because, to our knowledge, such platforms have not emerged in developing countries yet. Food waste is, however, also a critical problem in these countries, where it mainly emerges at the initial stages 
(post-harvest and processing) of the supply chain (FAO, n.d.). As there is growing attention for ways to employ digital technology and foster its widespread diffusion in developing countries in order to improve the livelihoods of the poor (Dahlman et al. 2016; Hanna 2017; Retamal and Dominish 2017), exploring the roles taken on by food waste platforms that will emerge in and/or expand to developing countries would be a highly valuable area for further investigation.

Finally, whereas this study adopted the perspective of the food waste platforms, research could also illuminate the behaviour of platform users vis-à-vis food waste. For example, it would be interesting to explore whether platforms have triggered deeper, more pervasive changes in users' behaviour towards waste, particularly with respect to waste prevention. Such an investigation might be able to shed light on whether and how the use of the platform has led to changes in consumers' purchase decision-making processes and in their buying behaviour. This would be another feasible quantitative follow-up research to our qualitative study.

Acknowledgements The authors would like to thank the platform organizations for their willingness to be interviewed and share detailed information about their roles and activities, and Merve Güvendik for bringing in her practical experience for the identification of the platforms, sketching developments in the circular economy area, and support with some of the skype interviews.

Funding The first author's research appointment was supported by a grant from the Netherlands Organisation for Scientific Research; the work contributes to the overarching programme on sustainable business models.

\section{Compliance with Ethical Standards}

Conflict of interest The authors declare that they have no conflict of interest.

Ethical Approval This paper does not contain any studies with human participants or animals performed by any of the authors.

Informed Consent Informed consent was obtained from all interviewees quoted in the study.

Open Access This article is distributed under the terms of the Creative Commons Attribution 4.0 International License (http://creativeco mmons.org/licenses/by/4.0/), which permits unrestricted use, distribution, and reproduction in any medium, provided you give appropriate credit to the original author(s) and the source, provide a link to the Creative Commons license, and indicate if changes were made.

\section{Appendix}

\section{Main Interview Questions}

- What role does platform $\mathrm{X}$ want to play in the fight against food waste?

- Why did you decide to use digital technology to address the issue of food waste?

- How do you work to convince potential users on the supply/demand side to use the platform and exchange food waste?

- What services do you offer users in relation to/beside the platform?

- What type of users does the platform target?

- What challenges have you faced? How have you addressed them?

- Have you developed collaborations/partnerships?

- What is your revenue model?

\section{References}

Acquier, A., Daudigeos, T., \& Pinkse, J. (2017). Promises and paradoxes of the sharing economy: An organizing framework. Technological Forecasting and Social Change, 125, 1-10.

Armstrong, M. (2006). Competition in two-sided markets. RAND Journal of Economics, 37(3), 668-691.

Beamon, B. M. (1998). Supply chain design and analysis: Models and methods. International Journal of Production Economics, 55(3), 281-294.

Borgatti, S. P., \& Li, X. (2009). On social network analysis in a supply chain context. Journal of Supply Chain Management, 45(2), 5-22.

Bowen, G. A. (2008). Naturalistic inquiry and the saturation concept: S research note. Qualitative Research, 8(1), 137-152.

Brouthers, K., Geisser, K., \& Rothlauf, F. (2016). Explaining the internationalization of ibusiness firms. Journal of International Business Studies, 47(5), 513-534.

Burt, R. S. (1992). Structural holes: The structure of competition. Cambridge, MA: Harvard University Press.

Burt, R. S. (2004). Structural holes and good ideas. American Journal of Sociology, 110(2), 349-399.

Burt, R. S. (2007). Second hand brokerage: Evidence on the importance of local structure for managers, bankers, and analysts. Academy of Management Journal, 50(1), 119-148.

Burt, R. S., Kilduff, M., \& Tasselli, S. (2013). Social network analysis: Foundations and frontiers on advantage. Annual Review of Psychology, 64, 527-547.

Chaabane, A., Ramudhin, A., \& Paquet, M. (2012). Design of sustainable supply chains under the emission trading scheme. International Journal of Production Economics, 135(1), 37-49.

Choi, T. Y., \& Wu, Z. (2009). Triads in supply networks: theorizing buyer-supplier-supplier relationships. Journal of Supply Chain Management, 45(1), 8-25.

Cicatiello, C., Franco, S., Pancino, B., Blasi, E., \& Falasconi, L. (2017). The dark side of retail food waste: Evidences from in-store data. Resources, Conservation and Recycling, 125, 273-281. 
Ciulli, F., \& Kolk, A. (2019). Incumbents and business model innovation for the sharing economy: Implications for sustainability. Journal of Cleaner Production, 214, 995-1010.

Collins-Dogrul, J. (2012). Tertius iungens brokerage and transnational intersectoral cooperation. Organization Studies, 33(8), 989-1014.

Corley, K. G., \& Gioia, D. A. (2004). Identity ambiguity and change in the wake of a corporate spin-off. Administrative Science Quarterly, 49(2), 173-208.

Cornelissen, J. P., \& Werner, M. D. (2014). Putting framing in perspective: A review of framing and frame analysis across the management and organizational literature. Academy of Management Annals, 8(1), 181-235.

Dahlman, C., Mealy, S., \& Wermelinger, M. (2016). Harnessing the digital economy for developing countries. OECD Development Center, Working Paper No. 334.

De la Fuente, M. V., Ros, L., \& Cardos, M. (2008). Integrating forward and reverse supply chains: Application to a metal-mechanic company. International Journal of Production Economics, 111(2), 782-792.

Devin, B., \& Richards, C. (2018). Food waste, power, and corporate social responsibility in the Australian food supply chain. Journal of Business Ethics, 150(1), 199-210.

Eckhardt, G. M., \& Bardhi, F. (2015). The sharing economy isn't about sharing at all. Harvard Business Review 28 January. Retrieved December 28, 2017 from https://hbr.org/2015/01/the-sharingeco nomy-isnt-about-sharing-at-all.

Edler, J., \& Yeow, J. (2016). Connecting demand and supply: The role of intermediation in public procurement of innovation. Research Policy, 45(2), 414-426.

Eisenhardt, K. M. (1989). Building theories from case study research. Academy of Management Review, 14(4), 532-550.

Eisenmann, T., Parker, G., \& Van Alstyne, M. W. (2006). Strategies for two-sided markets. Harvard Business Review, 84(10), 92-101.

Ellen MacArthur Foundation. (2013). Towards the circular economy, economic and business rationale for an accelerated transition. Cowes: Ellen MacArthur Foundation.

Ellis, P. D. (2003). Social structure and intermediation: Market-making strategies in international exchange. Journal of Management Studies, 40(7), 1683-1708.

Esposito, M., Tse, T., \& Soufani, K. (2018). Introducing a circular economy: New thinking with new managerial and policy implications. California Management Review, 60(3), 5-19.

Faccio, M., Persona, A., Sgarbossa, F., \& Zanin, G. (2014). Sustainable $\mathrm{SC}$ through the complete reprocessing of end-of-life products by manufacturers: A traditional versus social responsibility company perspective. European Journal of Operational Research, 233(2), 359-373.

FAO. (2011). Global food losses and food waste - Extent, causes and prevention. Rome: FAO.

FAO. (2017). Food loss and food waste. Retrieved May 20, 2018 from http://www.fao.org/food-loss-and-food-waste/en/.

FAO. (n.d.). Key facts on food loss and waste you should know! Retrieved December 14, 2017 from http://www.fao.org/savefood/resources/keyfindings/en/.

Filimonau, V., \& Gherbin, A. (2017). An exploratory study of food waste management practices in the UK grocery retail sector. Journal of Cleaner Production, 167, 1184-1194.

Firestone, W. A. (1993). Alternative arguments for generalizing from data as applied to qualitative research. Educational Researcher, 22(4), 16-23.

Fischer, A., \& Pascucci, S. (2017). Institutional incentives in circular economy transition: The case of material use in the Dutch textile industry. Journal of Cleaner Production, 155, 17-32.
Fiss, P. C., \& Zajac, E. J. (2006). The symbolic management of strategic change: Sensegiving via framing and decoupling. Academy of Management Journal, 49(6), 1173-1193.

Fleming, L., \& Waguespack, D. M. (2007). Brokerage, boundary spanning, and leadership in open innovation communities. Organization Science, 18(2), 165-180.

Flynn, B. B., Huo, B., \& Zhao, X. (2010). The impact of supply chain integration on performance: A contingency and configuration approach. Journal of Operations Management, 28(1), 58-71.

Frenken, K., \& Schor, J. (2017). Putting the sharing economy into perspective. Environmental Innovation and Societal Transitions, 23, 3-10.

Gaiani, S., Caldeira, S., Adorno, V., Segrè, A., \& Vittuari, M. (2018). Food wasters: Profiling consumers' attitude to waste food in Italy. Waste Management, 72, 17-24.

Garrone, P., Melacini, M., Perego, A., \& Sert, S. (2016). Reducing food waste in food manufacturing companies. Journal of Cleaner Production, 137, 1076-1085.

Gawer, A. (2014). Bridging differing perspectives on technological platforms: Toward an integrative framework. Research Policy, 43(7), 1239-1249.

Gehman, J., Glaser, V. L., Eisenhardt, K. M., Gioia, D., Langley, A., \& Corley, K. G. (2018). Finding theory-method fit: A comparison of three qualitative approaches to theory building. Journal of Management Inquiry, 27(3), 284-300.

Geissdoerfer, M., Morioka, S. N., de Carvalho, M. M., \& Evans, S. (2018). Business models and supply chains for the circular economy. Journal of Cleaner Production, 190, 712-721.

Geissdoerfer, M., Savaget, P., Bocken, N. M., \& Hultink, E. J. (2017). The circular economy: A new sustainability paradigm? Journal of Cleaner Production, 143, 757-768.

Genovese, A., Acquaye, A. A., Figueroa, A., \& Koh, S. L. (2017). Sustainable supply chain management and the transition towards a circular economy: Evidence and some applications. Omega, 66, 344-357.

Gioia, D. A., \& Chittipeddi, K. (1991). Sensemaking and sensegiving in strategic change initiation. Strategic Management Journal, 12(6), 433-448.

Gioia, D. A., Corley, K. G., \& Hamilton, A. L. (2013). Seeking qualitative rigor in inductive research: Notes on the Gioia methodology. Organizational Research Methods, 16(1), 15-31.

Gioia, D. A., Price, K. N., Hamilton, A. L., \& Thomas, J. B. (2010). Forging an identity: An insider-outsider study of processes involved in the formation of organizational identity. Administrative Science Quarterly, 55(1), 1-46.

Gioia, D. A., \& Thomas, J. B. (1996). Identity, image, and issue interpretation: Sensemaking during strategic change in academia. Administrative Science Quarterly, 41(3), 370-403.

Gioia, D. A., Thomas, J. B., Clark, S. M., \& Chittipeddi, K. (1994). Symbolism and strategic change in academia: The dynamics of sensemaking and influence. Organization Science, 5(3), 363-383.

Glaser, B., \& Strauss, A. (1967). The discovery of grounded theory. Chicago, IL: Aldine.

Gokarn, S., \& Kuthambalayan, T. S. (2017). Analysis of challenges inhibiting the reduction of waste in food supply chain. Journal of Cleaner Production, 168, 595-604.

Govindan, K., Soleimani, H., \& Kannan, D. (2015). Reverse logistics and closed-loop supply chain: A comprehensive review to explore the future. European Journal of Operational Research, 240(3), 603-626.

Graham-Rowe, E., Jessop, D. C., \& Sparks, P. (2014). Identifying motivations and barriers to minimising household food waste. Resources, Conservation and Recycling, 84, 15-23. 
Guide, V. D. R., \& Van Wassenhove, L. N. (2006). Closed-loop supply chains: An introduction to the feature issue (part 2). Production and Operations Management, 15(4), 471-472.

Guide, V. D. R., \& Van Wassenhove, L. N. (2009). The evolution of closed-loop supply chain research. Operations Research, 57(1), 10-18.

Hanna, N. K. (2017). How can developing countries make the most of the digital revolution? Retrieved December 14, 2018 from http://blogs.worldbank.org/ic4d/how-can-developing-count ries-make-most-digital-revolution.

Hargadon, A., \& Sutton, R. I. (1997). Technology brokering and innovation in a product development firm. Administrative Science Quarterly, 42(4), 716-749.

Hebrok, M., \& Boks, C. (2017). Household food waste: Drivers and potential intervention points for design: An extensive review. Journal of Cleaner Production, 151, 380-392.

Holt, D., \& Ghobadian, A. (2009). An empirical study of green supply chain management practices amongst UK manufacturers. Journal of Manufacturing Technology Management, 20(7), 933-956.

Holweg, C., Teller, C., \& Kotzab, H. (2016). Unsaleable grocery products, their residual value and instore logistics. International Journal of Physical Distribution \& Logistics Management, 46(6/7), 634-658.

Hunt, S. D., \& Vitell, S. (1986). A general theory of marketing ethics. Journal of Macromarketing, 6(1), 5-16.

Hyde, C. A. (2003). Multicultural organization development in nonprofit human service agencies: Views from the field. Journal of Community Practice, 11(1), 39-59.

Jacobides, M. G., Cennamo, C., \& Gawer, A. (2018). Towards a theory of ecosystems. Strategic Management Journal, 39(8), 2255-2276.

Jang, S. (2017). Cultural brokerage and creative performance in multicultural teams. Organization Science, 28(6), 993-1009.

Jin, L., \& Robey, D. (1999). Explaining cybermediation: An organizational analysis of electronic retailing. International Journal of Electronic Commerce, 3(4), 47-66.

Jones, T. M. (1991). Ethical decision making by individuals in organizations: An issue-contingent model. Academy of Management Review, 16(2), 366-395.

Kaine, S. J., \& Josserand, E. (2018). Mind the gap: Grass roots 'brokering' to improve labour standards in global supply chains. Human Relations, 71(4), 584-609.

Kannothra, C. G., Manning, S., \& Haigh, N. (2018). How hybrids manage growth and social-business tensions in global supply chains: The case of impact sourcing. Journal of Business Ethics, 148(2), 271-290.

Kirkels, Y., \& Duysters, G. (2010). Brokerage in SME networks. Research Policy, 39(3), 375-385.

Kjærgaard, A., Morsing, M., \& Ravasi, D. (2011). Mediating identity: A study of media influence on organizational identity construction in a celebrity firm. Journal of Management Studies, 48, 514-543.

Knox, B. D. (2018). Employee volunteer programs are associated with firm-level benefits and CEO incentives: Data on the ethical dilemma of corporate social responsibility activities. Journal of Business Ethics. https://doi.org/10.1007/s10551-018-4005-0.

Korstjens, I., \& Moser, A. (2018). Series: Practical guidance to qualitative research. Part 4: Trustworthiness and publishing. European Journal of General Practice, 24(1), 120-124.

Kortmann, S., \& Piller, F. (2016). Open business models and closedloop value chains: Redefining the firm-consumer relationship. California Management Review, 58(3), 88-108.

Kumar, V., Holt, D., Ghobadian, A., \& Garza-Reyes, J. A. (2015). Developing green supply chain management taxonomy-based decision support system. International Journal of Production Research, 53(21), 6372-6389.

Kyprianou, C. (2018). Creating value from the outside in or the inside out: How nascent intermediaries build peer-to-peer marketplaces. Academy of Management Discoveries. https://doi.org/10.5465/ amd.2017.0081.

Langley, A., \& Abdallah, C. (2011). Templates and turns in qualitative studies of strategy and management. In D. Bergh \& D. Ketchen (Eds.), Building methodological bridges: Research methodology in strategy and management (Vol. 6, pp. 201-235). Bingley: Emerald Group.

Laurell, C., \& Sandstrom, C. (2017). The sharing economy in social media: Analyzing tensions between market and non-market logics. Technological Forecasting and Social Change, 125, 58-65.

Lieder, M., \& Rashid, A. (2016). Towards circular economy implementation: A comprehensive review in context of manufacturing industry. Journal of Cleaner Production, 115, 36-51.

Lincoln, Y. S., \& Guba, E. G. (1985). Naturalistic inquiry. Beverly Hills, CA: Sage.

Lingo, E. L., \& O’Mahony, S. (2010). Nexus work: Brokerage on creative projects. Administrative Science Quarterly, 55(1), 47-81.

Linton, J. D., Klassen, R., \& Jayaraman, V. (2007). Sustainable supply chains: An introduction. Journal of Operations Management, 25(6), 1075-1082.

Locke, K. (2001). Grounded theory in management research. Thousand Oaks, CA: Sage.

Lüdeke-Freund, F., Gold, S., \& Bocken, N. M. (2019). A Review and typology of circular economy business model patterns. Journal of Industrial Ecology, 23(1), 36-61.

Manning, S., \& Roessler, D. (2014). The formation of cross-sector development partnerships: How bridging agents shape project agendas and longer-term alliances. Journal of Business Ethics, 123(3), 527-547.

Marsden, P. V. (1982). Brokerage behavior in restricted exchange networks. In P. V. Marsden \& N. Lin (Eds.), Social structure and network analysis (pp. 201-218). Beverly Hills, CA: Sage.

McIntyre, D. P., \& Srinivasan, A. (2017). Networks, platforms and strategy: Emerging views and next steps. Strategic Management Journal, 38(1), 141-160.

Michelini, L., Principato, L., \& Iasevoli, G. (2018). Understanding food sharing models to tackle sustainability challenges. Ecological Economics, 145, 205-217.

Mourad, M. (2016). Recycling, recovering and preventing 'food waste': Competing solutions for food systems sustainability in the United States and France. Journal of Cleaner Production, 126, 461-477.

Muriana, C. (2017). A focus on the state of the art of food waste/losses issue and suggestions for future researches. Waste Management, $68,557-570$.

Murillo, D., Buckland, H., \& Val, E. (2017). When the sharing economy becomes neoliberalism on steroids: Unravelling the controversies. Technological Forecasting and Social Change, 125, 66-76.

Murray, A., Skene, K., \& Haynes, K. (2017). The circular economy: An interdisciplinary exploration of the concept and application in a global context. Journal of Business Ethics, 140(3), 369-380.

Nag, R., \& Gioia, D. A. (2012). From common to uncommon knowledge: Foundations of firm-specific use of knowledge as a resource. Academy of Management Journal, 55(2), 421-457.

Obstfeld, D. (2005). Social networks, the tertius iungens orientation, and involvement in innovation. Administrative Science Quarterly, 50(1), 100-130.

Ojala, A., Evers, N., \& Rialp, A. (2018). Extending the international new venture phenomenon to digital platform providers: A longitudinal case study. Journal of World Business, 53(5), 725-739. 
Östlin, J., Sundin, E., \& Björkman, M. (2008). Importance of closedloop supply chain relationships for product remanufacturing. International Journal of Production Economics, 115(2), 336-348.

Pagell, M., \& Wu, Z. (2009). Building a more complete theory of sustainable supply chain management using case studies of 10 exemplars. Journal of Supply Chain Management, 45(2), 37-56.

Pagotto, M., \& Halog, A. (2016). Towards a circular economy in Australian agri-food industry: An application of input-output oriented approaches for analyzing resource efficiency and competitiveness potential. Journal of Industrial Ecology, 20(5), 1176-1186

Papargyropoulou, E., Lozano, R., Steinberger, J. K., \& Wright, N. (2014). The food waste hierarchy as a framework for the management of food surplus and food waste. Journal of Cleaner Production, 76, 106-115.

Parker, G. G., Van Alstyne, M. W., \& Choudary, S. P. (2016). Platform revolution: How networked markets are transforming the economy and how to make them work for you. New York: W. W. Norton \& Company.

Patton, M. Q. (1980). Qualitative research and evaluation methods. London: Sage.

Pollock, T. G., Porac, J. F., \& Wade, J. B. (2004). Constructing deal networks: Brokers as network 'architects' in the US IPO market and other examples. Academy of Management Review, 29(1), $50-72$.

Quintane, E., \& Carnabuci, G. (2016). How do brokers broker? Tertius gaudens, tertius iungens, and the temporality of structural holes. Organization Science, 27(6), 1343-1360.

Ranjan, K. R., \& Read, S. (2016). Value co-creation: Concept and measurement. Journal of the Academy of Marketing Science, 44(3), 290-315.

Rao, P., \& Holt, D. (2005). Do green supply chains lead to competitiveness and economic performance? International Journal of Operations \& Production Management, 25(9), 898-916.

Reinecke, J., \& Ansari, S. (2015). When times collide: Temporal brokerage at the intersection of markets and developments. Academy of Management Journal, 58(2), 618-648.

Rest, J. R. (1986). Moral development: Advances in research and theory. New York: Praeger.

Retamal, M., \& Dominish, E. (2017). The sharing economy in developing countries. Tearfund: Institute for Sustainable Futures, University of Technology Sydney.

Ribeiro, I., Sobral, P., Peças, P., \& Henriques, E. (2018). A sustainable business model to fight food waste. Journal of Cleaner Production, 177, 262-275.

Richter, B., \& Bokelmann, W. (2018). The significance of avoiding household food waste: A means-end-chain approach. Waste Management, 74, 34-42.

Risi, D., \& Wickert, C. (2017). Reconsidering the 'symmetry' between institutionalization and professionalization: The case of corporate social responsibility managers. Journal of Management Studies, 54(5), 613-646.

Rochet, J.-C., \& Tirole, J. (2003). Platform competition in two-sided markets. Journal of the European Economic Association, 1, 990-1029.

Sakaguchi, L., Pak, N., \& Potts, M. D. (2018). Tackling the issue of food waste in restaurants: Options for measurement method, reduction and behavioral change. Journal of Cleaner Production, 180, 430-436.

Saldaña, J. (2013). The coding manual for qualitative researchers. Thousand Oaks, CA: Sage.

Saunders, L. W., Tate, W. L., Zsidisin, G. A., \& Miemczyk, J. (2017). The influence of network exchange brokers on sustainable initiatives in organizational networks. Journal of Business Ethics. https://doi.org/10.1007/s10551-017-3436-3.
Schanes, K., Dobernig, K., \& Gözet, B. (2018). Food waste matters: A systematic review of household food waste practices and their policy implications. Journal of Cleaner Production, 182, 978-991.

Schenkel, M., Krikke, H., Caniëls, M. C., \& van der Laan, E. (2015). Creating integral value for stakeholders in closed loop supply chains. Journal of Purchasing and Supply Management, 21(3), $155-166$.

Schwartz, M. S. (2016). Ethical decision-making theory: An integrated approach. Journal of Business Ethics, 139(4), 755-776.

Searcy, C. (2012). Corporate sustainability performance measurement systems: A review and research agenda. Journal of Business Ethics, 107(3), 239-253.

Sert, S., Garrone, P., Melacini, M., \& Perego, A. (2018). Corporate food donations: Altruism, strategy or cost saving? British Food Journal, 120(7), 1628-1642.

Seuring, S., \& Müller, M. (2008). From a literature review to a conceptual framework for sustainable supply chain management. Journal of Cleaner Production, 16(15), 1699-1710.

Shah, S. K., \& Corley, K. G. (2006). Building better theory by bridging the quantitative-qualitative divide. Journal of Management Studies, 43(8), 1821-1835.

Smaling, A. (1992). Varieties of methodological intersubjectivity: The relations with qualitative and quantitative research, and with objectivity. Quality \& Quantity, 26(2), 169-180.

Sonenshein, S. (2007). The role of construction, intuition, and justification in responding to ethical issues at work: The sensemaking-intuition model. Academy of Management Review, 32(4), 1022-1040.

Sonenshein, S. (2014). How organizations foster the creative use of resources. Academy of Management Journal, 57(3), 814-848.

Stadtler, L., \& Probst, G. (2012). How broker organizations can facilitate public-private partnerships for development. European Management Journal, 30(1), 32-46.

Stancu, V., Haugaard, P., \& Lähteenmäki, L. (2016). Determinants of consumer food waste behaviour: Two routes to food waste. Appetite, 96, 7-17.

Stangherlin, I. D. C., \& de Barcellos, M. D. (2018). Drivers and barriers to food waste reduction. British Food Journal, 120(10), 2364-2387.

Stovel, K., \& Shaw, L. (2012). Brokerage. Annual Review of Sociology, 38, 139-158.

Strauss, A., \& Corbin, J. (1990). Basics of qualitative research. Newbury Park, CA: Sage.

Thøgersen, J., \& Ölander, F. (2003). Spillover of environment-friendly consumer behaviour. Journal of Environmental Psychology, 23(3), 225-236.

Thomas, L. D., Autio, E., \& Gann, D. M. (2014). Architectural leverage: Putting platforms in context. Academy of Management Perspectives, 28(2), 198-219.

Thyberg, K. L., \& Tonjes, D. J. (2016). Drivers of food waste and their implications for sustainable policy development. Resources, Conservation and Recycling, 106, 110-123.

Tse, T., Esposito, M., \& Soufani, K. (2016). How businesses can support a circular economy. Retrieved May 20, 2018 from https:// hbr.org/2016/02/how-businesses-can-support-a-circular-econo my.

United Nations. (1997). Glossary of environment statistics, studies in methods, Series F, No. 67, New York.

Van Burg, E., Berends, H., \& Van Raaij, E. M. (2014). Framing and interorganizational knowledge transfer: A process study of collaborative innovation in the aircraft industry. Journal of Management Studies, 51(3), 349-378.

World Bank. (2014). Food loss and waste a barrier to poverty reduction. Retrieved May 20, 2018 from http://www.worldbank.org/ 
en/news/press-release/2014/02/27/food-loss-waste-barrier-pover ty-reduction.

Yoo, Y., Henfridsson, O., \& Lyytinen, K. (2010). Research commentary: The new organizing logic of digital innovation: An agenda for information systems research. Information Systems Research, 21(4), 724-735.

Zhu, F., \& Liu, Q. (2018). Competing with complementors: An empirical look at Amazon.com. Strategic Management Journal, 39(10), 2618-2642.
Publisher's Note Springer Nature remains neutral with regard to jurisdictional claims in published maps and institutional affiliations. 